University of Rhode Island

DigitalCommons@URI

Open Access Master's Theses

1973

\title{
Solubilization of Hydrocarbons by Dissolved Organic Matter in Sea Water
}

Paul David Boehm

University of Rhode Island

Follow this and additional works at: https://digitalcommons.uri.edu/theses

\section{Recommended Citation}

Boehm, Paul David, "Solubilization of Hydrocarbons by Dissolved Organic Matter in Sea Water" (1973).

Open Access Master's Theses. Paper 2079.

https://digitalcommons.uri.edu/theses/2079

This Thesis is brought to you for free and open access by DigitalCommons@URI. It has been accepted for inclusion in Open Access Master's Theses by an authorized administrator of DigitalCommons@URI. For more information, please contact digitalcommons-group@uri.edu. 


\author{
SOLUBILIZATION OF HYDROCARBONS BY \\ DISSOLVED ORGANIC MATTER IN SEA WATER \\ BY \\ PAUL DAVID BOEHM
}

A THESIS SUBMITTED IN PARTIAL FULFILINENT OF THE REQUIREMENTS FOR THE DEGREE OF

MASTER OF SCIENCE

IN

OCEANOGRAPHY

UNIVERSITY OF RHODE ISLAND

1973 


\section{ABSTRACT}

Water samples from Narragansett Bay, the Providence River, the Sargasso Sea, and fulvic acid/saline (NaCl) solutions were examined for their ability to solubilize $n$-alkane $\left(n-c_{16}, n-c_{20}\right)$, isoprenoid (pristane), naphthenic (tetradecahydrophenanthrene) and aromatic (phenanthrene, anthracene) hydrocarbons. A 30-80\% reduction in the dissolved organic content of the natural samples by activated charcoal and by ultraviolet oxidation resulted in a 50-99\% decrease in the amount of saturated hydrocarbons solubilized. This decrease was directly related to the amount of dissolved organic matter (D.O.M.) removed. The solubilities of the aromatic hydrocarbons were unaffected by the D.O.M. The solubility of phenanthrene is twenty times greater than its structural isomer, anthracene, regardless of the concentration of D.O.M.

Fulvic acid from a marine sediment, surface active organic material isolated at a chloroform/sea water interface, organic material extracted from a marine sediment by sea water, organic matter associated with a municipal. sewage effluent, fulvic acid from a muck soil, and humic acid from a marine sediment promote n-alkane solubility when added to saline solutions and reenhance solubility when added to organic depleted sea water. The solubility of No. 2 fuel oil increased 2.5 times in the presence of 
fulvic acid in saline solutions and was 1.5 to 2.0 times greater in Narragansett Bay water than in charcoal treated bay water. Most of the increase is seen in the n-alkane and isoprenoid components of the fuel oil.

$\mathrm{N}$-alkane solubility increases in fulvic acld/saline solutions with increasing $\mathrm{pH}$ and reaches a maximum with respect to ionic strength at $I=0.3$ in $\mathrm{NaCl}$ solutions and at $I=0.2$ in sea water. There is evidence to suggest that the mode of solubilization of the hydrocarbons is by association with micelles formed by the surface-active humiclike monomers. The presence of ionic species is a prerequisite for micelle formation and hence solubilization. The surface microlayer of the Sargasso Sea, which was enriched 1.8 times in dissolved organic carbon relative to the subsurface water, solubilized n-alkane hydrocarbons while the subsurface water showed no ability to solubilize these materials. 


\section{ACKNOW,EDGMENTS}

I have been most fortunate during the past two years in being associated with Dr.. James G. Quinn. Always genuineIy interested in my work, he has taught me much of what I know about careful scientific research and has advised me throughout the course of this work.

Deserving of thanks are Drs. Robert Duce, G.T. Felbeck, and Charlie Olney who read this manuscript and offered valuable suggestions as to how to improve it.

The course of my academic life has changed during the past four years. Instrumental in changing my direction, both academically and personally, has been Ellen (Elenita), my wife and my helmsperson. It was she who first pointed me towards oceanography as a profession. She has been a constant source of energy and inspiration to me. Every word in this thesis is dedicated to her; indeed, every word has been typed by her.

This investigation supported by funds from the the National Sea Grant Program, National Oceanic and Atmospheric Administration (04-3-158-3) and the offices of the International Decale of Ocean Exploration, National Science Foundation (GX-33777). For the past two years I have been supported by the Environmental Protection Agency training grant, T-900140. 
Too much too soon, too easy too fast While the earth slipped through our fingers we tried to hold to what can't last. In a land so rich, in a land so strong You'd think we'd have the time by now to tell right from wrong.

Peter Rowan

"Seatrain" 1971 
TABLE OF CONTENTS

I- INTRODUCTION . . . . . . . . . . . . I

Intent

Approach

II- LITERATURE REVIEW . . . . . . . . . . . 4

Hydrocarbon SoIubility

Solubilization of Non-electrolytes

organic Macromolecules (Humic Substances)

in Sea Water

Interaction of Humic Material and Hydrophobic Organic Compounds

III- EXPERTMENTAL . . . . . . . . . . . . 1 ?

General

Hydracarbon Solubilization Systems

Fuel OII Solubility

Gas Chromatographic Analyses

Dissolved Organic Carbon Removal

Fulvic Acid and Humic Acid Stock Solution Preparation

DissoIved Organic Carbon Analyses

NaturaI Sea Water and Saline Water Sample

ChemicaIs

Preparation

Blaniks

IV- Results and Díscussion. . . . . . . . . 28

The Basic Hydrocarbon System

The Effect of Dissolved Organic Carbon Removal

Ultraviolet Oxidation Study

The Effect of Readdition of Fulvic Acid from

SeveraI Sources

Hydrocarbon Solubility in Open Ocean Waters

The Effect of Filter Pore Size on Hydrocarbon Solubility

The Effect of Salinity

The Effect of $\mathrm{pH}$

The Influence of a Sewage Effluent

The Effect of Fulvic Acid and Natural Dissolved Organic Matter on the Solubility of Fuel Oil

Micelle Formation and Solubilization by Surfactant Humic Material

V- SUMMARY. . . . . . . . . . . . 86

VI- IIST OF REFERENCES. . . . . . . . . . 88 


\section{IIST OF TABIES}

Table

Page

1. Hydrocarbon Solubilities of Various Systems in Narragansett Bay Water. . . . . . . 32

2. The Effect of a Reduction in the Dissolved Organic Carbon Concentration of Sea Water on Hydrocarbon Solubility. . . . . . . 39

3. The Effect of a Reduction in the Dissolved Organic Carbon Concentration of Sea Water on the Solubility of Various Hydrocarbons and a Phthalic Acid Ester. . . . . . . . 4 43

4. Hydrocarbon Solubilities; Ultraviolet Oxidation and Fulvic Acid studies. . . . . . . 45

5. Solubility of Hydrocarbons in Natural WatersSolubilization at the Surface Microlayer . . 53

6. Hydrocarbon Solubility in a Sewage Effluent and in Providence River Water Samples. . . . 69

7. Solubility of Fuel oil in Fulvic Acid Solutions and in Narragansett Bay Water. . . . . 78 


\section{LIST OF ILLUSTRATIONS}

Figure

Page

1. The Effect of the Quantity of Hexadecane Added on its Solubility ir Fulvic Acid/Saline Water

Solution ........... 30

2. Effect of Increasing the Shaking Time on

Hydrocarbon Solubility in a Fulvic Acid/Saline

Water Solution . . . . . . . . . 35

3. Effect of Increasing the Standing Time on

Hydrocarbon Solubility in a Fulvic Acid/Saline

Water Solution . . . . . . . . . 37

4. The Solubility Reduction of Hexadecane upon

Removal of Natural Dissolved Organic Carbon

with Activated Charcoal from Narragansett

Bay Water. ............ . 41

5. Solubility of Hexadecane as a Function of the

Amount of Alkaline Sediment Extract (Fulvic

Acid) Added to Saline Water. . . . . . 48

6. The Relationship of Hexadecane Solubility in

Providence River Water to Cellulose Acetate

Filter Pore Size. . . . . . . . 57

7. Hydrocarbon Solubility as a Function of Salinity . 60

8. Hydrocarbon Solubility as a Function of pH. . . . 66

9. Solubility of Number 2 Fuel Oil: GIC Chromatograms75 


\section{I-INTRODUCTION}

Organic geochemistry is a scientific discipline dealing with the study of the source, nature and fate of biogenic organic compounds in terrestrial and marine geological environments. One of the major endeavors in this discipline is the study of the diagenesis or the change with time of these compounds. An understanding of the close association of sea water organic chemistry and marine organic geochemistry is of fundamental importance in the understanding of both of these disciplines. The chemical and physical processes occurring in sea water which serve to transport and to alter these biogenic compounds have in the past been less studied than the post-depositional sedimentary processes. Recently, the tools which were originally developed for the study of biogeochemistry (as organic geochemistry is often referred to) have been utilized in the investigation of the fate of organic pollutants in natural waters and in sediments.

The sea water transport of biogenic and pollutant organic chemicals results in biological (on a short time scale) and geological sinks, i.e. ingestion (assimilation) or sedimentation. Processes which tend to promote the formation of particulate material (e.g. adsorption and flocculation) affect organisms differently than processes involved in dissolution and/or solubilization phenomena. How such 
processes in sea water act on these organic chemicals is a study linking marine biochemistry, sea water organic chemistry, and organic geochemistry to each other.

Hydrophobic organic materials have been found in close association with terrestrial humic materials. It is probable that if the bulk of the organic matter dissolved in sea water is indeed humic-like as postulated by several investigators, a similar association and interaction could be expected in ocean waters.

\section{Intent}

The intent of this study is to further the understanding of the natural chemical transporting mechanisms in sea water that act on hydrocarbons from their point of injection to their ultimate biological and geological fates.

\section{Approach}

A laboratory study investigating the role of natural surfactants (i.e. organic macromolecules) in the process of increasing the solubility of hydrocarbons was undertaken. Organic macromolecules (humic material) from a number of sources, both terrestrial and marine, were studied for their ability to solubilize hydrocarbons. The behavior of different hydrocarbon compounds representing the main classes of hydrocarbons which comprise petroleum (paraffins, 
naphthenes, aromatics) and the behavior of fuel oil itself, in this solubilization process was investigated. A number of experimental factors were studied to determine their influence on the solubilization phenomena ( $\mathrm{g} . \mathrm{g}$. shaking time, filter pore size, etc.). Furthermore several environmental factors were experimentally varied to learn of their effect on the hydrocarbon solubilization by the naturally occuring surfactants (e.g. pH, salinity).

Experimental conditions were established to reflect natural conditions and processes wherever possible. In this way, the ultimate objective of this study, which is to determine the role of the dissolved organic matter in sea water in mobilizing and transporting pollutant hydrocarbons, could best be achieved. 


\section{II-IITERATURE REVIEW}

Hydrocarbon Solubility

When a hydrocarbon molecule is introduced into water, it is immediately subjected to a number of possible fates: evaporation; chemical, photochemical and biological oxidation; adsorption at a solid-liquid or gaseous-liquid interface; dissolution and solubilization. The predominance and the rate of any of these processes is dependent upon a number of chemical properties of the hydrocarbon molecule: chain length (molecular weight), degree of unsaturation, degree of aromaticity, degree of chain branching. Dissolution is a physical process which affects the lower molecular weight members of a given homologous series to a greater extent than any higher molecular weight member (i.e. solubility decreases with increasing molar volume within each homologous series) (McAuliffe, 1966; 1969). McAuliffe (1966) investigated the dependence of hydrocarbon water solubility on molecular structure and showed the following trends: 1) branching increases water solubility for paraffin, olefin and acetylene hydrocarbons, but not for cycloparaffin or aromatic compounds. (He postulated that this is an effect due not to structural features, but to the higher vapor pressure of the branched chain hydrocarbons relative to the straight chain compounds.) 2) Ring formation increases water solubility for a given carbon number, 3) Increasing unsatu- 
ration increases water solubility, and 4) A triple bond increases water solubility to a greater extent than two double bonds. McAuliffe realized that studies of hydrocarbon "solubility" are actually studies in accommodation of these hydrophobic materials into the water structure. Hence, any discussion of hydrocarbon solubility does not refer to a true dissolution process as that which occurs with ionic species and to some extent with ionizable organic materials. The existence of a hydrophobic species in water causes: 1) an increase in the structuring of the water about the hydrophobic material, 2) a curtailment of the configurational possibilities available to the hydrocarbons which are in an interstitial solution (Frank and Franks, 1965) and hence 3) an increase in the free energy and a decrease in the entropy of the system. Thus, the trends $(1-4)$ seen above are rooted in these thermodynamic considerations and are most readily seen in the trend towards lower "solubility" within all homologous series with increasing molar volume. Franks (1966), investigating the dependence of solubility on chain length of n-paraffins, found that $\Delta G^{\circ}$ (the standard free energy change associated with the transfer of a gaseous hydrocarbon to aqueous solution) was minimal for n-pentane $\left(n-C_{5}\right)$ indicating maximim solubility for this hydrocarbon. The values increased to a maximum $\Delta G^{0}$ for $\mathrm{n}-\mathrm{C}_{10}$ and then decreased to $\mathrm{n}-\mathrm{C}_{16}$ indicating that long chain hydrocarbons are more soluble than would be expected from an extension of $\Delta G^{\circ}$ values for shorter chain members. Baker 
(1967) also found anomolously high solubility values for long chain paraffins. The data of McAuliffe (1969), Franks (1966) and Baker (1967) indicate that a change from true solubility to one of accommodation occurs at $n-C_{11}$. This change from actual incorporation in the water structure to accommodation was seen by Baker (1967) to reflect intermolecular association or aggregation of $n$-paraffin monomers which he compared to the micellar structures of dilute solutions of colloidal electrolytes.

The only thorough study of the accommodation of long chain n-alkanes in water was made by Peake and Hodgson (1966, 1967). They examined a distilled water system and studied the effect of filtration on the accommodated hydro carbons, investigated the effect of the presence of surfactants (benzoic acid, nonadecanoic acid, and cyclohexanecarboxylic acid), studied the effect of increasing alkalinity and examined the behavior of multicomponent systems. They were able to elucidate a few main trends: 1) filtration reduced the amount of hydrocarbons accomodated, 2) accommodation values generally fell in the range 100 to $0.01 \mathrm{mg} /$ liter from $n-C_{12}$ to $n-C_{35}$, 3) liquid hydrocarbons enhanced the accommodation of solid hydrocarbons in multicomponent systems, 4) the accommodation process was dependent on experimental history (i.e. hydrocarbon supply, shaking and settling times, mode of intorduction, etc.), 5) increased alkalinity increased hydrocarbon accommodation, and 6) the presence of surfactants had little effect on increasing 
accommodation values.

The trends seen in the above studies should ideally be applicable to any hydrocarbon mixture including petroleum and petroleum products. Petroleum is composed of thousands of individual compounds; but can be classified for an "average" crude oil as follows, according to Koons (1973):

By molecular size: gasoline $\left(C_{5}-C_{10}\right) ; 30 \%$

kerosene $\left(\mathrm{C}_{10}-\mathrm{C}_{12}\right): 10 \%$

1 ig ht distillate oil $\left(c_{12}-c_{20}\right), 15 \%$

heavy distillate oil $\left(\mathrm{C}_{20}-\mathrm{C}_{40}\right), 25 \%$

extremely heavy residuum oil $\left(>C_{40}\right), 20 \%$

By molecular type: paraffin hydrocarbons (alkanes), 30\% naphthene hydrocarbons (cycloalkanes). aromatics, $15 \%$ polar nitrogen, sulfur and oxygen $50 \%$ containing compounds, $5 \%$.

Very few determinatios of petroleum solubility in water have been attempted. The most recent was that by Boylan and Tripp (1971) who partially characterized sea water extracts of crude oil by gas-liquid chromatography and mass spectometry, without attempting to determine the effect of insoluble droplets in the aqueous extracts. They determined that the concentration of naphthalene in sea water extracts of kerosene and Kuwait crude oil were 159.9 and $32.3 \mu \mathrm{g} / 1$ respectively and that the total amount of oil in the crude oil extract was $1453 \mu \mathrm{g} / \mathrm{I}(657 \mu \mathrm{g}$ benzenes and naphthalenes and 796 kg polar aromatics.)

It is apparent that the only study discussed to this point that deals with sea water is Boylan and Tripp's (1971). However; Gordon and Thorne $(1967 \mathrm{a}, \mathrm{b})$ have investigated the 
effects of salts on the solubility of naphthalene in natural and artificial sea rater. The relationship of the molar solubility (S) of a non-electrolyte, the activity coefficient $(f)$, and the molar salt concentration $\left(C_{s}\right)$ was first discovered by Setschenow (1889):

$$
\log \left(f / f^{0}\right)=\log \left(S^{0} / S\right)-K C_{S}
$$

(The superscript zero indicates pure water.) Gordon and Thorne (1967a) showed that the salt effect of mixtures of inorganic salts on sólubility was additive:

$$
\log s=\log s^{0}-\sum \mathrm{N}_{i} K_{i} C_{t}
$$

(where $\mathrm{N}_{i}$ and $\mathrm{K}_{i}$ are the mole fraction and Setschenow constant of the $i^{\text {th }}$ component). They also showed that naphthalene was salted out by sea salt according to the equation:

$$
\log s=-3.59-0.2564 c_{t}
$$

with no difference seen between artificial and natural sea water. They concluded that "the solubility of non-polar non-electrolytes in sea water can be quantitatively accounted for...by consideration of only the major electrolyte constituents. No solubilization by dissolved organic matter is detectible." (Gordon and Thorne, 1967b). The solubility of naphthalene in sea water was determined to be approximately $26 \mathrm{mg} / \mathrm{l}$ in a $0.5 \mathrm{~m}$ mixed salt artificial sea water and approximately $250 \mathrm{mg} / 1$ when $0.1 \mathrm{~mole} / 1$ of sodium decanoate surfactant was added. Their samples were filtered and solubility was determined by measuring the optical density of the filtrate. These values differ by three to four orders of magnitude from Boylan and Tripp's (1971) data, 
thus illustrating that although the two studies are not directly related and used different methods of analysis, non-electrolyte solubility determinations are largely dependent on experimental history.

\section{Solubilization of Non-electrolytes}

As mentioned above, Gordon and Thorne (1967b) found no evidence for solubilization of the aromatic hydrocarbon, naphthalene, in sea water. They did, however, show that solubilization occurs at surfactant concentrations above the critical micelle concentration (CMC), (i.e. that surfactant concentration at which micellization and hence solubilization first occur.)

A few definitions are in order. Solubilization may be defined as the process of increasing the solubility of a water insoluble or sparingly soluble organic material, in a surfactant solution, or the "preparation of a thermodynamically stable isotropic solution of a substance normally insoluble or very slightly soluble in a given solvent by the introduction of an additional amphiphilic (having an affinity for both polar and non-polar solutions) component or components" (Elworthy et al., 1969). The aggregation of single surfactant molecules (those having a hydrophobic, non-polar end and a hydrophilic, polar end) to form colloidal particles with non-polar regions closely associated together, separated from the polar medium (e.g. water) by the 
polar head groups, is termed micellization. The micelles thus formed are capable of incorporating non-polar solutes within the hydrophobic regions of the micelle. This transfer of the hydrocarbon from water to the hydrophobic region of the micelle results in an entropy advantage for the system, even though the formation of the micelle itself results in an entropy decrease. Micelle formation results in a reduction of interfacial free energy between the hydrophobic end of the surfactant monomer and the water molecules. Solubilization also achieves a reduction in interfacial energy for solute (hydrocarbon) monomers. Micelles need not be spherical. They appear to be hydrated structures spherical in dilute solutions and assymmetrical in concentrated solutions (Elworthy et al., 1969). Indeed, the shape of the micelle depends on the surfactant molecular shape and hence on molecular complexity. Many factors affect the solubilization phenomenon: added electrolytes (ionic strength), the nature of the surfactant and its concentration, the solubilizate type and its concentration, temperature, etc. and these will receive further attention in later sections of this thesis.

In his discussion on the origin of crude oil, Baker (1960) suggested that crude oil consists of hydrocarbons that were once solubilized in formation waters that might contain natural solubilizers, which he thought to be related to water soluble salts of organic acids (e.g. sodium naphthenate). Gordon and Thome (1967b) discuss solubiliza- 
tion of hydrocarbons in sea water. They observed that there does not exist enough lipid material in sea water which could potentially be called micelle forming, and which could bring about solubilization except in "some coastal waters at some times". Curiously, no one has considered a possible role for the major fraction of dissolved organic material in seawater, the so-called humic substances, which are surface-active macromolecules and which may comprise as much as $90 \%$ of the dissolved organic matter in sea water (Williams 1971. Duursma 1965. Degens 1970).

Organic Macromolecules (humic substances) in Sea Water The naturally occuring dissolved organic material (D.O.M.) in sea water includes thousands of compounds which are present in a total concentration ranging from 0.3 to $20 \mathrm{mg} / \mathrm{I}$ (Riley and Chester, 1971), the higher values occuring in some richly productive coastal waters and the lower in some open ocean waters of low nutrient concentrations and hence low productivity. Dissolved organic carbon (D.O.C.) values in ocean waters most commonly range from $0.5 \mathrm{mg} \mathrm{C} / 1$, for deep water, to about $3 \mathrm{mg} \mathrm{c} / 1$ for productive coastal surface waters. The classes of compounds most thoroughly studied include the lipids (fatty acids, hydrocarbons, pigments, fatty alcohols), the carbohydrates, and the amino acids. (Wagner 1969). Williams (1971) reported a breakdown for the characterized $10 \%$ of D.0.M. to be : 
$2.5 \%$ amino acids, $1 \%$ sugars, $4 \%$ fatty acids, $2 \%$ urea and 1\% aromatics. These percentages surely vary from area to area, from day to day, and within the water column. As these materials comprise about $10-20 \%$ of the dissolved organic matter in sea water, it is clear that the major fraction of the D.O.M. has not yet been fully characterized. The macromolecular organic components in this fraction have molecular weights ranging from several hundred to several hundred thousand (Khaylov, 1968), and have been referred to as humic substances (Prakash and Rashid, 1968), water humus (Skopintsev, 1950), yellow substances and Gelbstoffe (Kalle, 1966). While there is general agreement that the macromolecules contain both aromatic and aliphatic units at the molecular "backbone" and contain carboxyl, phenolic, and alcoholic functional groups, the use of the terminology "humic material" to characterize these substances in sea water is not universally accepted and perhaps considered somewhat premature. Indeed there is only scant evidence indicating the relationship of the macromolecules to conventional humic material as found in soils and in marine sediments.

The phraseology "humic material" is a general classification of organic materials operationaliy broken down into humic, fulvic, and hymatomelonic acids and humin based on the conventional fractionation scheme which depends on soiubility behavior of the various fractions in base, acid, and alcohol (see Schnitzer and Khan, 1973, Pierce and Felbeck, 
1973). There is undoubtedly much overlap in this crude fractionation scheme, but the acid soluble, base soluble fraction (fulvic acid) is of lower molecular weight, has a greater number of oxygen containing functional groups and is hence more water soluble than the base soluble, acid insoluble humic acid (Schnitzer and Khan, 1973).

Theories as to the synthesis of these macromolecules in sea water have been inferred from the findings of soil chemists (e.g. Felbeck, 1971, Flaig, 1971) as well as presented for their in situ formation by Kalle (1966), Sieburth and Jensen, (1968), Nissenbaum and Kaplan (1972) and others. Kalle (1966) proposed a melanoidine synthesis between carbohydrates and amino acids as accounting for much of the UV absorbing and fluorescing material in ocean water. The role of the phaeophyceae in Gelbstoffe formation in coastal waters due to exudations of phenolic material was discussed by Sieburth and Jensen (1969). Evidence for the in situ formation of marine humics from planktonic degradation products in the ocean was presented by Nissenbaum and Kaplan (19.72). These authors first published the scheme interrelating plankton and humic acids. the degradation and transition scheme of plankton $\rightarrow$ degraded cellular material $\rightarrow$ water soluble amino acid-carbohydrate complex $\rightarrow$ fulvic acid $\rightarrow$ humic acid $\rightarrow$ kerogen, which was based on isotopic and chemical evidence. others have studied the contribution of marine algae to the ocean's dissolved organic matter (D.O.M.) specifically relating algal decomposition products to the humic-like materials in natural waters, in marine sediment, and in soils 
(e.g. Rashid and Prakash, 1972; Akiyama, 1972; Khailov and Burlakova, 1972). However, our knowledge of the chemical and physical properties of these important and complex materials is still quite meager. Menzel and Ryther (1970) and Williams and Gordon (1970) conclude that below a depth of about 300 meters, the dissolved organic carbon can be considered to be a conservative property, (concentration = $0.3-0.8 \mathrm{mg} \mathrm{c} / 1$ ) its age (based on radiocarbon dating) being 3400 years as determined in the northeast Pacific ocean (Williams, 1971).

Interaction of Humic Material and Hydrophobic Organic Compounds

Only recently has the association between soil fulvic and humic acids and hydrophobic organic compounds been established (Khan and Schnitzer, 1972; Ogner and Schnitzer, 1970 a,b; Schnitzer and ogner, 1970). These authors showed that both fulvic and humic acids could fix and retain alkanes, fatty acids and dialkyl phthalates. They suggested that these lipophilic materials are fixed to the humic substances by incorporation into a molecular sieve-type structure comprised of hydrogen bonded phenolic and benzenecarboxylic acids. The hydrophobic materials are presumably adsorbed onto the surface of the molecule as well as incorporated into void spaces of a macromolecular clathrate structure. Meyers and Quinn (1973) found that indigenous dissolved. organic matter in sea water and soil fulvic acid in saline 
solutions reduced the adsorption of fatty acids by clays. The authors attributed these findings to possible solubilization of the fatty acids by these organic materials, thus decreasing their adsorption by minerals.

The interaction of soil organic matter with organic pollutants was studied by Wershaw and Burcar (1967), and Wershaw et al. (1969). Two different types of interactions were postulated; solubilization of otherwise water insoluble compounds by surface-active sodium humate salts and adsorption on the molecular surfaces of the less soluble humic acid. Their investigation of the interaction of DDT with sodium humate and humic acid showed the two mechanisms operating simultaneously as predicted.

There is undoubtedly a very close relationship between humic materials in marine sediments and dissolved macromolecules in sea water. The fulvic acid $\rightarrow$ humic acid transformation discussed by Sieburth and Jensen (1968) and Nissenbaum and Kaplan (1972) has important implications for the dispersion, transport and sedimentation of associated hydrophobic organic compounds and the migration and accumulation of petroleum source material. Furthermore, the role of terrestrial humic materials, most importantly water soluble fulvic acid, in estuarine and coastal environments in the mobilization and transport of lipophilic pollutants surely merits detailed study. The large amounts (50\%) of organic material in sewage effluents resembling humic substances (Rebhun and Manka, 1971) that are introduced in 
coastal areas also may play an important role in pollutant mobilization.

In this study I have attempted to investigate the behavior of various components of petroleum, including individual and combined aliphatic and aromatic systems, emphasizing the essential role that dissolved organic matter in sea water plays in the process of accommodation. (The term accommodation will henceforth be referred to in this study as solubilization). From these various experiments an attempt has been made to define the mode of existence of hydrocarbons in sea water, and the basic mechanism of the solubilization process. 


\section{III-EXPERIMENTAL}

\section{General}

There has been in the past no universally accepted procedure for determining the solubility of non-polar materials (hydrocarbons, etc.) in water. The naive approach would have been to proceed in a manner similar to the determination of inorganic salt solubility, which is straightforward and involves addition of the solute in excess to the water, followed by perhaps heating, then cooling, and finalIy a filtering or decantation step. The solubility would then be determined indirectly by measuring that material being held on the filter. However, in studying hydrocarbon solubility and solubilization phenomena the term "solubility" is purely operational. There is no dissociation of the solute; the solute may be present as monomers, but more likely as small aggregates or droplets. It is the specifics of the final filtration that determines that which is "soluble" and that which is not. This is not to say that other researchers have not reported hydrocarbon solubility without a filtration step. However, it seemed that the logical way to proceed with a solubility determination of this nature was to adhere to the operational definition of dissolved organic matter in the ocean - that material which passes a $0.5 \mu$ filter (Strickland and Parsons, 1972; Riley and Chester, 1971). other factors that will affect solubility values are 
adsorption to glassware and hence the glassware's surface area, the mode of introduction of the hydrocarbon, the quantities of hydrocarbons used, the method and time of shaking, the time of settling or standing and the volume of the solution used in the determination. The main guiding light in the selection of the experimental method was to approximate that which would occur in the ocean as best as could be achieved within the framework of a small scale laboratory investigation. The second consideration was that of expedience which involved establishing a relatively rapid, reproducible procedure in conjunction with ease of analysis. Fortunately, the two were able to be followed without concentrating on one to the exclusion of the other.

\section{Hydrocarbon Solubilization Systems}

The n-alkane hydrocarbons hexadecane $\left(n-C_{16}\right)$ and eicosane $\left(n-c_{20}\right)$ and the aromatic hydrocarbon phenanthrene (phen) were dissolved in acetone and added in various combinations to a $100 \mathrm{ml}$ screw-capped centrifuge tube. The acetone was then evaporated on a rotary flash evaporator at room temperature $\left(20-25^{\circ} \mathrm{C}.\right)$. For most studies the quantities in micrograms of the hydrocarbons added were $n-C_{16}: n-C_{20}:$ Phen $=200$ : $200: 40$ or $200: 0: 40$. In some studies anthracene, dibutyl phthalate or tetradecahydrophenanthrene (TDHP) were substituted for phenanthrene and in another pristane for hexadecane. One hundred milliters (ml) of test solution were added and the tube and its contents were shaken for 30 minutes in 
a metabolic shaker (Precision Scientific Company, Chicago 120 shakes/minute, amplitude $5 \mathrm{~cm}$.) and then allowed to stand undisturbed for 30 minutes. All experiments were run at room temperature. The solution was vacuum filtered (200 $\mathrm{mm} \mathrm{Hg}$ vacuum) through a $5.5 \mathrm{~cm}$ (diameter) Whatman GF/C glass

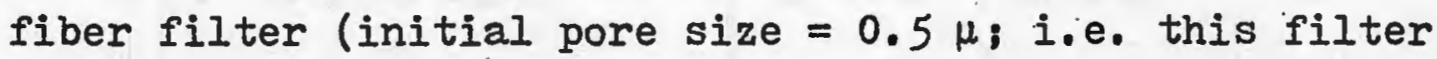
retains greater than $99 \%$ of particles with a diameter of $0.5 \mu$ and greater.) which was first pre-washed in methanol and distilled water. The filtration was halted before the filter was dry to avoid excessive disruption of hydrocarbon droplets and colloidal material. To the filtered solution, now in a $250 \mathrm{ml}$ vacuum filtering flask, $50 \mu \mathrm{g}$ of $\mathrm{n}-\mathrm{C}_{22}$ (docosane) internal standard was added in $0.5 \mathrm{ml}$ acetone and the solution was thoroughly mixed. Fifty ml of petroleum ether (b.r. $30-60^{\circ} \mathrm{C}$ ) were added and the solution was extracted with vigorous shaking for one minute. The petroleum ether phase was isolated and evaporated to dryness at room temperature in a rotary flash evaporator. The residue, containing the solubilized hydrocarbon(s) was dissolved in carbon disulfide and analyzed by gas-liquid chromatography (GLC). Evaporation loss of the most volatile component, $n-C_{16}$, was $5 \%$ and losses in the extraction and evaporation amounted to a total of $7 \%$ both losses relative to recovery of the internal standard.

A hydrocarbon balance on the entire system was made. This involved proceeding with a solubility determination as outlined above and washing all of the apparatus with dis- 
tilled methanol followed by petroleum ether. After this procedure a standard hydrocarbon $\left(n-C_{22}\right)$ was added to the wash from the centrifuge tube, from the filtering apparatus, and an internal standard $\left(n-C_{22}\right)$ to the filtrate. The amounts of hydrocarbons in the washings were added to the values for the filtrate (or the solubilized hydrocarbons) and gave the following recoveries based on the recovery of the hydrocarbon mixture evaporated under vacuum to dryness and analyzed also by GLC: $n-C_{16}=100 \% \pm 3 \%: n-C_{20}=103 \%$ $\pm 3 \%$. Phenanthrene $=91 \% \pm 3 \%$. The final location of the hydrocarbons as determined by this balance was: n-alkanes$15 \%$ soluble (i.e. passing the filter) $45 \%$ remaining in the centrifuge tube, $40 \%$ on the filter and filtering apparatus; phenanthrene - 55\% soluble, $30 \%$ in the tube, $15 \%$ on the filter assembly. The precision (relative standard deviation) of the solubility method was $\pm 16 \%$ for $n-C_{16}$ and $\pm 12 \%$ for phenanthrene, as determined on six replicates.

\section{Euel Oil Solubility}

Two experiments were performed to determine the solubility behavior of No 2 fuel oil. To one liter of saline water $(30 \% \mathrm{NaCl})$ and one liter of a fulvic acid/saline water solution (D.O.C. $=3.72 \mathrm{mg} /$ liter), or to one liter of Narragansett Bay water and one liter of charcoal treated (organic "free") Bay water, each in one liter separatory funnels, $4 \mathrm{mg} \mathrm{No.} 2$ fuel oil were added. The funnels were shaken for 15 minutes and allowed to stand for 30 minutes. 
The water was drained leaving $5 \mathrm{ml}$ in the funnel (this $5 \mathrm{ml}$ contained any surface oil film) and the $995 \mathrm{ml}$ sample was filtered under vacuum through a Whatman GF/C filter. Twenty micrograms of $n-C_{22}$ intermal standard were added in $0.2 \mathrm{ml}$ acetone to the filtrate, the mixture was shaken, $500 \mathrm{ml}$ of petroleum ether were added and the water was extracted for one minute. The petroleum ether phase was isolated and evaporated on a rotary flash evaporator. The residue was then analyzed by GLC. For the solubility determinations on Narragansett Bay water the fuel oil was spiked with $n-C_{20}$ (docosane) in the ratio of $1 \mathrm{mg}$ docosane per $15 \mathrm{mg}$ fuel oil and the spiked mixture used instead of unadulterated fuel oil. The precision of these determinations based on duplicate samples for fuel oil solubility in Narragansett Bay water was $\pm 20 \%$ for total hydrocarbon values.

\section{Gas Chromatographic Analyses}

Analysis of the hydrocarbons was performed on a Hewlett-Packard Model 700 flame ionization gas chromatograph equipped with a $3.3 \mathrm{~mm}$ o.d. (2.2 mm i.d.) by $2.1 \mathrm{~m}$ stainless steel column packed with $2 \%$ OV-I on 100/110 mesh Anakrom Q. The column was operated isothermally at $180^{\circ} \mathrm{C}$ at a flow rate of $35 \mathrm{ml}$ of nitrogen per minute and at an inlet pressure of 50 psig.

The areas of the hydrocarbon peaks were compared to the area of the internal standard peak to quantitate the 
results. The areas were measura: by multiplying height by width at half peak height.

Analysis of the fuel oil samples was performed on a Hewlett-Packard Model 5750 flame ionization gas chromatograph. The column $(2.1 \mathrm{~m})$ was $3.2 \mathrm{~mm} 0 . \mathrm{d}^{\mathrm{g}}(2.2 \mathrm{~mm}$. i.d.) stainless steel packed with $3 \%$ Apiezon I on Chromosorb W, 80-100 mesh, and was temperature programmed from $140^{\circ} \mathrm{C}$ to $280^{\circ} \mathrm{C}$ at $8^{\circ} \mathrm{C}$ per minute at a nitrogen flow rate of $10 \mathrm{ml}$ per minute at 50 psig inlet pressure.

The fuel oil chromatograms were quantified using a planimeter to measure areas.

\section{Dissolved Organic Carbon Removal}

Removal of the organic matter in sea water was accomplished using $80 / 100$ mesh activated charcoal (Bameby-Cheney gas chromatographic grade), which was preignited at $700^{\circ} \mathrm{C}$ for four hours. The charcoal was then prewashed with 1 liter of distilled water. A slight organic bleed from the charcoal into the distilled water was noticed. The D.0.C. of the distilled water prior to the wash was $0.12 \mathrm{mg} \mathrm{c} / 1 \pm$ 0.05 and after the wash it increased to $0.47 \pm 0.12$. After the distilled water wash no organic bleed was noticed when saline water was slurried with the washed charcoal. The washed charcoal was continously slurried with one liter of the sea water or fulvic acid/saline. water solution for one hour at room temperature. The slurry was then vacuum fil- 
tered through a Gelman A glass fiber filter (initial pore size $=0.3 \mu)$. Slurrying at the level of 5 grams of charcoal per liter achieved a $35 \%$ to $90 \%$ removal of the D.0.C. with most values falling between $60-80 \%$. The $\mathrm{pH}$ of the solutions prepared in this manner increased slightly. Therefore the $\mathrm{pH}$ was adjusted to the initial solution value. The salinities remained constant throughout this procedure.

Photolytic oxidation using ultraviolet destruction as performed by Armstrong et al. (1966) was carried out on 50 $\mathrm{ml}$ water samples in $100 \mathrm{ml}$ stoppered quartz tubes. Approximately 0.1 - $0.2 \mathrm{ml}$ of $30 \% \mathrm{H}_{2} \mathrm{O}_{2}$ were added prior to oxidation. A 1200 watt mercury arc lamp was used for irradiation for four hours. The ambient temperature in the reaction was about $70^{\circ} \mathrm{C}$. The simultaneous irradiation of twelve tubes was achieved by using a circular apparatus with a lamp at the center. This method destroyed more than $90 \%$ of the D.0.C. with no appreciable $\mathrm{pH}$ or salinity changes.

Fulvic Acid and Humic Acid Stock Solution Preparation

One hundred grams of a Narragansett Bay sediment (station $E_{2}, 9.84 \mathrm{mg}$ organic carbon/gram dry weight, Farrington and Quinn, 1973a) air dried and sieved through a $1 \mathrm{~mm}$ screen, was extracted with $500 \mathrm{ml}$ of $0.5 \mathrm{~N} \cdot \mathrm{NaOH}$ for six hours at room temperature utilizing a magnetic stirring apparatus. After filtration through a Whatman No. I filter paper the filtrate was acidified to $\mathrm{pH}$ equal to 2.0 with $1.0 \mathrm{~N} \mathrm{HCl}$. The solu- 
tion, after standing for an hour, was filtered through a Gelman A filter. The final brownish solution contained 175 mg carbon. The solution was neutralized to $\mathrm{pH}=7.5$ with 1. $\mathrm{ON} \mathrm{NaOH}$ and stored at $0^{\circ} \mathrm{C}$. The material retained by the Gelman A filter (i.e. humic acid) was redissolved in $100 \mathrm{ml}$ $0.5 \mathrm{~N} \mathrm{NaOH}$, and the solution's $\mathrm{pH}$ adjusted to approximately 8.0. The black humic acid solution obtained contained $64 \mathrm{mg}$ carbon. Thus approximately $25 \%$ of the sediment's organic carbon was extracted as humic and fulvic acids.

Fulvic acid from a muck soil was prepared by R. Pierce according to procedure number 1 of Pierce and Felbeck (1973). The stock solution was prepared by dissolving $21.5 \mathrm{mg}$ of fulvic acid in $75 \mathrm{ml} 0.5 \mathrm{~N} \mathrm{NaOH}$.

Dissolved Organic Carbon (D.O.C.) Analysis

The analysis for D.O.C. was similar to that described by Menzel and Vaccaro (1964) and further studied by Williams (1969). Four ml 3\% $\mathrm{H}_{3} \mathrm{PO}_{4}$ and 2 grams $\mathrm{K}_{2} \mathrm{~S}_{2} \mathrm{O}_{8}$ were added to $100 \mathrm{ml}$ of the sample water and the mixture stirred until all components were fully dissolved. From this solution (104 ml) $10 \mathrm{ml}$ aliquots were transferred to preignited glass ampoules $\left(500^{\circ} \mathrm{C}\right.$ for 4 hours). This procedure was slightly modified during this study by adding $\mathrm{K}_{2} \mathrm{~S}_{2} \mathrm{O}_{8}(0.2 \mathrm{~g})$ directly to the ampoule prior to the addition of the sample/phosphoric acid mixture. The samples were purged with nitrogen, sealed and then oxidized in an autoclave at $115^{\circ} \mathrm{C}$ for $2 \frac{1}{2}$ hours. oxida- 
tion was also performed in an oven held at $110^{\circ} \mathrm{C}$ for 2 hours. The results were identical to those with samples heated in the autoclave. The analyses were performed on a Beckman IR analyzer (model 215) or an oceanography Intermational total carbon analyzer (model 0524). The results were obtained by using calibration curves of sucrose and glucose. Increasing oxidation time showed that no further oxidation takes place beyond $2 \frac{1}{2}$ hours when natural sea water samples or fulvic acid/saline water solutions were analyzed. The precision of the method was $\pm 0.1 \mathrm{mg} \mathrm{C} / 1$ on samples of 0.5 to $20 \mathrm{mg}$ carbon $/ 1$.

Analysis of a soil fulvic acid for percent carbon by dry combustion using a $C: H: N$ analyser gave a value of $34.3 \% \mathrm{C}$. Dissolved organic carbon analysis of a stock solution of this fulvic acid, converted to percent carbon, gave a value of $35.7 \% \mathrm{C}$ using wet combustion and analysis by I.R. absorption as discussed above. Thus the two methods of analysis yield very similar results.

Natural Sea Water and Saline Water Sample Preparation

Narragansett Bay water was collected sporadically throughout the year from the dock of the Graduate School of Oceanography located in the West Passage of Narragansett Bay. The water was vacuum filtered through a Gelman A glass fiber filter prior to use in all of the solubility determinations using natural dissolved organic matter. Saline water 
solutions were prepared using preignited sodium chloride $\left(500^{\circ} \mathrm{C}\right.$ for four hours) and distilled water and all salinities determined by using a hand held refractometer, $( \pm 0.5$ ppt). The salinity of the saline water test solution was $30 \%$ except where salinity was studied as a variable, and the $\mathrm{D} \cdot 0 . \mathrm{C} .=0.2 \mathrm{mg} \mathrm{C} / \mathrm{l}$. All $\mathrm{pH}$ adjustments were made using 1. $\mathrm{ON} \mathrm{HCl}$ and $0.5 \mathrm{~N} \mathrm{NaOH.} \mathrm{The} \mathrm{pH}$ of all saline water or fulvic acid/saline water test solutions was always in the range 7.2 to 8.0 unless $\mathrm{pH}$ was studied as a variable. The fulvic acid and humic acid stock solutions were prefiltered through a Gelman A filter immediately before adding to saline water for solubility determinations. Upon addition to saline water the stock solution did not affect the pH of the media as the stock solutions were stored at $\mathrm{pH}=8.0$. The salinity was likewise unaffected due to the small volumes of stock solutions added.

\section{Chemicals}

All chemicals used other than hydrocarbons were A.C.S. reagent grade and the organic solvents were distilled in an all glass still fitted with a $30 \mathrm{~cm}$ Widmer column. The $\mathrm{n}-$ alkanes were high purity $(>99 \%)$ grade obtained from Analabs Inc. (North Haven, Conn.). Phenanthrene, anthracene, dibutyl phthalate and TDHP were obtained from Eastman Kodak Co. (Rochester, N.Y.) 
Blanks

Samples of sea water and fulvic acid/saline water solutions were extracted and analyzed by GLC thus combining sample and reagent blanks. Only trace quantities of total material (less than $0.1 \mu g$ ) were found in all blanks by GIC. analysis. Values given in the tables have been corrected for this blank material where applicable. 


\section{IV-RESULTS AND DISCUSSION}

Throughout this presentation soluble hydrocarbons are defined as those hydrocarbons passing a $0.5 \mu$ filter (Riley and Chester, 1971; Strickland and Parsons, 1972) and solubilization as the process resulting in passage of the hydrocarbons by this filter.

\section{The Basic Hydrocarbon System}

To approximate the quantitative interaction of sea water and hydrocarbons which may occur in the marine environment, a $200 \mu \mathrm{g} / 100 \mathrm{ml}$ limit of individual hydrocarbon concentration was used. This appeared to be a realistic value for heavy oil contamination as well as an experimentally convenient concentration. Higher concentrations were avoided to eliminate problems of readsorption of hydrocarbons from solution and phase separation which were observed using hydrocarbon concentrations higher than $400 \mu \mathrm{g} / 100 \mathrm{ml}$ (Fig l).

The solubility behavior of the n-alkanes hexadecane (m.p. $\left.=18.2^{\circ} \mathrm{C}\right)$ and eicosane $\left(\mathrm{m}_{*} \mathrm{p}_{\mathrm{s}}=36.8^{\circ} \mathrm{C}\right)$ a liquid and a solid respectively at the temperature at which all experiments were performed, $\left(20-25^{\circ} \mathrm{C}\right)$, and a solid polycyclic aromatic, phenanthrene $\left(\mathrm{m} . \mathrm{p} .=10 \mathrm{I}^{\circ} \mathrm{C}\right)$ was thoroughly studied as these compounds represented classes of compounds found in most crude and fuel oils. All experiments were internally 
FIGURE 1.--The effect of the quantity of hexadecane added on its solubility in fulvic acid/saline vater solution $(D .0 . C .=3.7 \mathrm{mg} \mathrm{C} / \mathrm{I})$ 


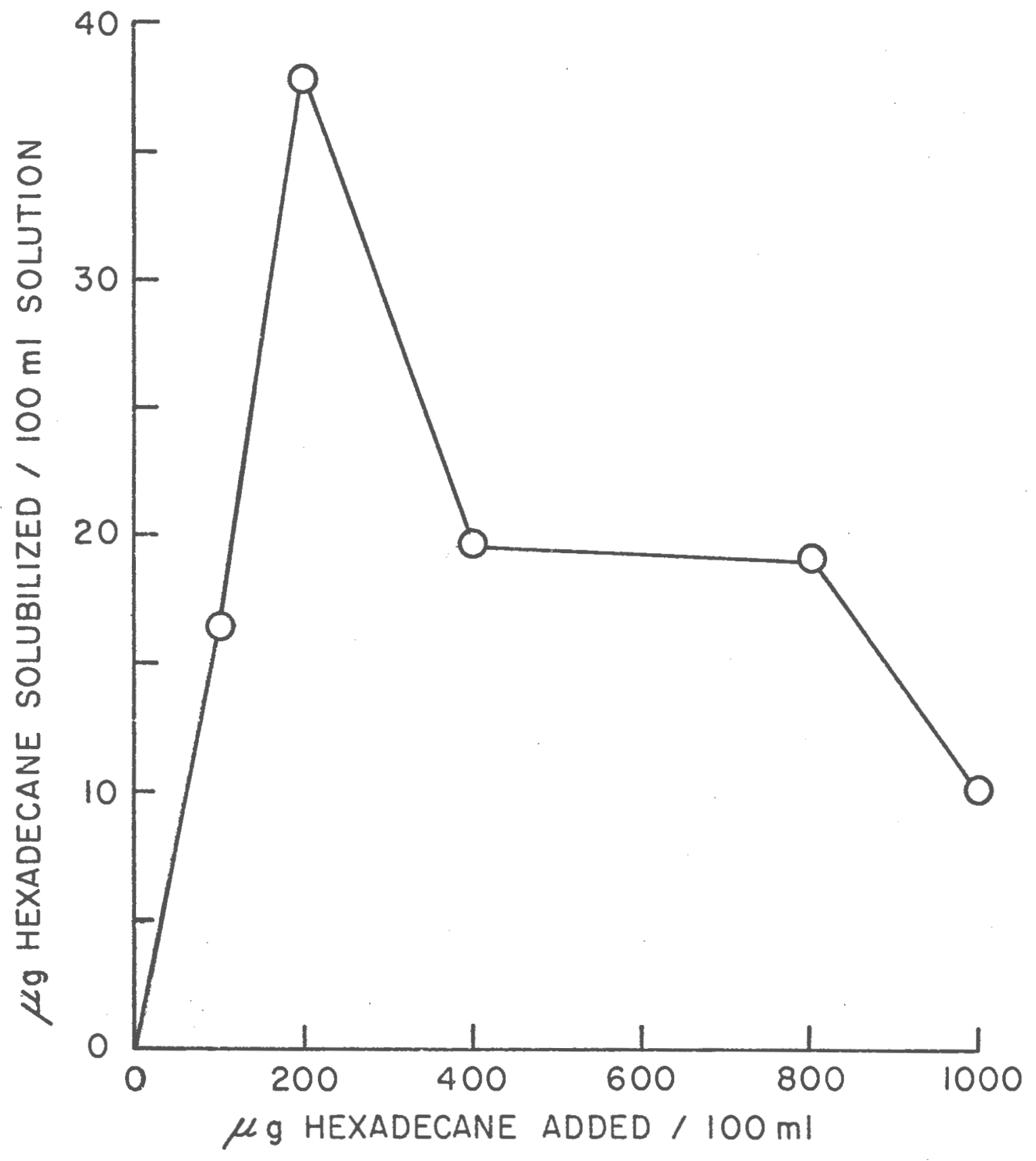

FULVIC ACID / SALINE SOLUTION 
consistent within each separate run. Absolute values were examined within each run and not compared between different runs using different water samples. No attempt has been made to report values for "absolute hydrocarbon solubility in sea water" because these values were dependent upon the experimental system and on conditions for each run. This study was concerned with the characteristics of the interaction of natural dissolved organic matter with petroleumlike hydrocarbons rather than absolute quantitative aspects of the data.

To assess the interactions of the two $n$-alkanes and the aromatic hydrocarbon, all combinations were investigated. The main features of the system are illustrated in Table 1 , systems 1-7. Phenanthrene is quite water soluble and is not systemmatically affected by the presence of the n-alkanes (systems 3,5,6,7). (Phenanthrene added to Narragansett Bay water at the concentrations of $1.0 \mathrm{mg} / 100 \mathrm{ml}, 0.5 \mathrm{mg} / 100 \mathrm{ml}$ and $0.1 \mathrm{mg} / 100 \mathrm{ml}$ yielded solubility values consistently in the range of 60 to $70 \mu \mathrm{g} / 100 \mathrm{ml})$. Eicosane is not appreciably solubilized in the absence of hexadecane (system 2 vs.4) an observation made also by Peake and.Hodgson (1967). Eicosane solubility decreases in the presence of phenanthrene but $n-C_{16}$ does not. (system 2 and 5 vs. 1 and 6 ). Hexadecane solubility decreases in the presence of eicosane (system 1 vs. 4). Thus it would appear that the $n$-alkanes are influenced by each other and are subject to the same mechanism of solubilization as evidenced by the nearly constant 
TABLE I

HYDROCARBON SOLUBILITIES OF VARIOUS SYSTEMS IN NARRAGANSETT BAY WATER

\begin{tabular}{|c|c|c|c|c|c|c|c|c|c|}
\hline $\begin{array}{l}\text { System } \\
\text { Number }\end{array}$ & $\begin{array}{c}\text { Hydrocar } \\
n-C_{16}\end{array}$ & 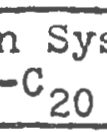 & te & hen & $\begin{array}{l}\text { Solubi } \\
n-C_{16}\end{array}$ & II & $\begin{array}{r}i t y(\mu \\
n-c_{20}\end{array}$ & 8 & $\begin{array}{l}00 \mathrm{ml}) \\
\text { Phen }\end{array}$ \\
\hline 1 & $200:$ & 0 & $:$ & 0 & 44.9 & 8 & $-\infty$ & 8 & -- \\
\hline 2 & 0. & 200 & : & 0 & $-\infty$ & 8 & 2.5 & 8 & -- \\
\hline 3 & $0:$ & 0 & 8 & 40 & -- & $:$ & $-\infty$ & 8 & 23.5 \\
\hline 4 & $200:$ & 200 & 8 & 0 & 37.0 & $:$ & 18.5 & 8 & - \\
\hline 5 & 08 & 200 & 8 & 40 & $-\infty$ & 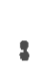 & 1.0 & 8 & 26.7 \\
\hline 6 & $200:$ & 0 & 8 & 40 & 46.7 & 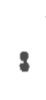 & $\therefore$ & 8 & 20.5 \\
\hline 7 & 2008 & 200 & 8 & 40 & 31.3 & 8 & 15.3 & $:$ & 22.6 \\
\hline
\end{tabular}

* Water sample : Narragansett Bay water--dissolved organic carbon $=2.94 \mathrm{mg} /$ liter $; \mathrm{pH}=7.7$, salinity $=27 \%$ 
values for the total $n-C_{16}+n-c_{20}(45-56 \mu g)$ (see systems $1,4,6,7)$. They do not appear to act in conjunction with phenanthrene to any great extent at the concentrations * studied (system 4 and 7 ). The solubilities of the $n$-alkanes decreased markedly if introduced levels were upwards of 400 $\mu \mathrm{g} / 100 \mathrm{ml}$ (Fig 1), probably due to adsorption of solubilized material on insoluble n-alkane droplets during the standing phase and phase separation.

The shaking and standing times (both 30 minutes) were chosen for experimental converience. The solubilization of the hydrocarbons is definitely related to these parameters, Figures 2 and 3, but it is not clear how increasing these times would better approximate real conditions. It is interesting to note that Pigures 2 and 3 again indicate the parallel behavior of the n-alkanes and the dissimilar behavior of phenanthrene. The marked decrease in the quantity of hydrocarbons passing the filter can in both figures be attributed to readsorption on container walls or to hydrocarbon aggregation. Samples shaken for more than 30 minutes showed a rapid decrease in n-alkane solubility. Phenanthrene equilibrates with the system after 1 hour and its solubility is unaffected by further shaking. N-alkane solubility in samples allowed to stand uniformly decreased almost tenfold in 160 hours, while phenanthrene was seen to slowly increase to a maximum value at approximately 50 hours and then gradually decrease to $70 \%$ of its 30 minute value.

To examine the solubilization phenomenon it was deemed 
FIGURE 2.--Effect of increasing the shaking time on hydrocarbon solubility in a fulvic acid/saline water solution $(D .0 . C$. $=3.72 \mathrm{mg} \mathrm{C} / 1$ )

- Hexadecane
Aicosane
Phenanthrene 


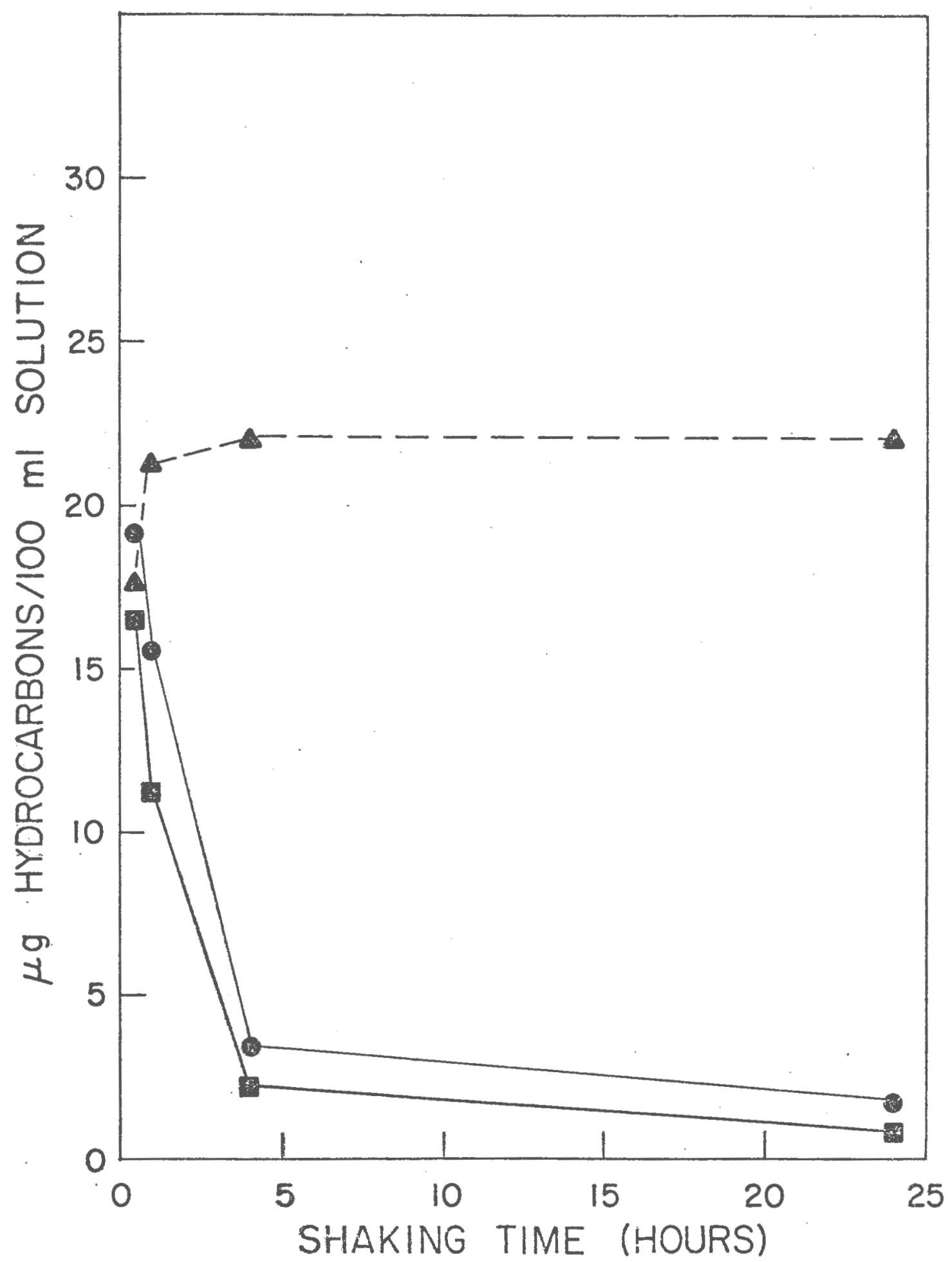


FIGURE 3.--Effect of increasing the standing time on hydrocarbon solubility in a fulvie acid/saline water solution $\quad(\mathrm{D} .0 . \mathrm{C} .=3.72 \mathrm{mg} \mathrm{C} / \mathrm{l})$

Hexadecane
Eicosane
Phenanthrene 


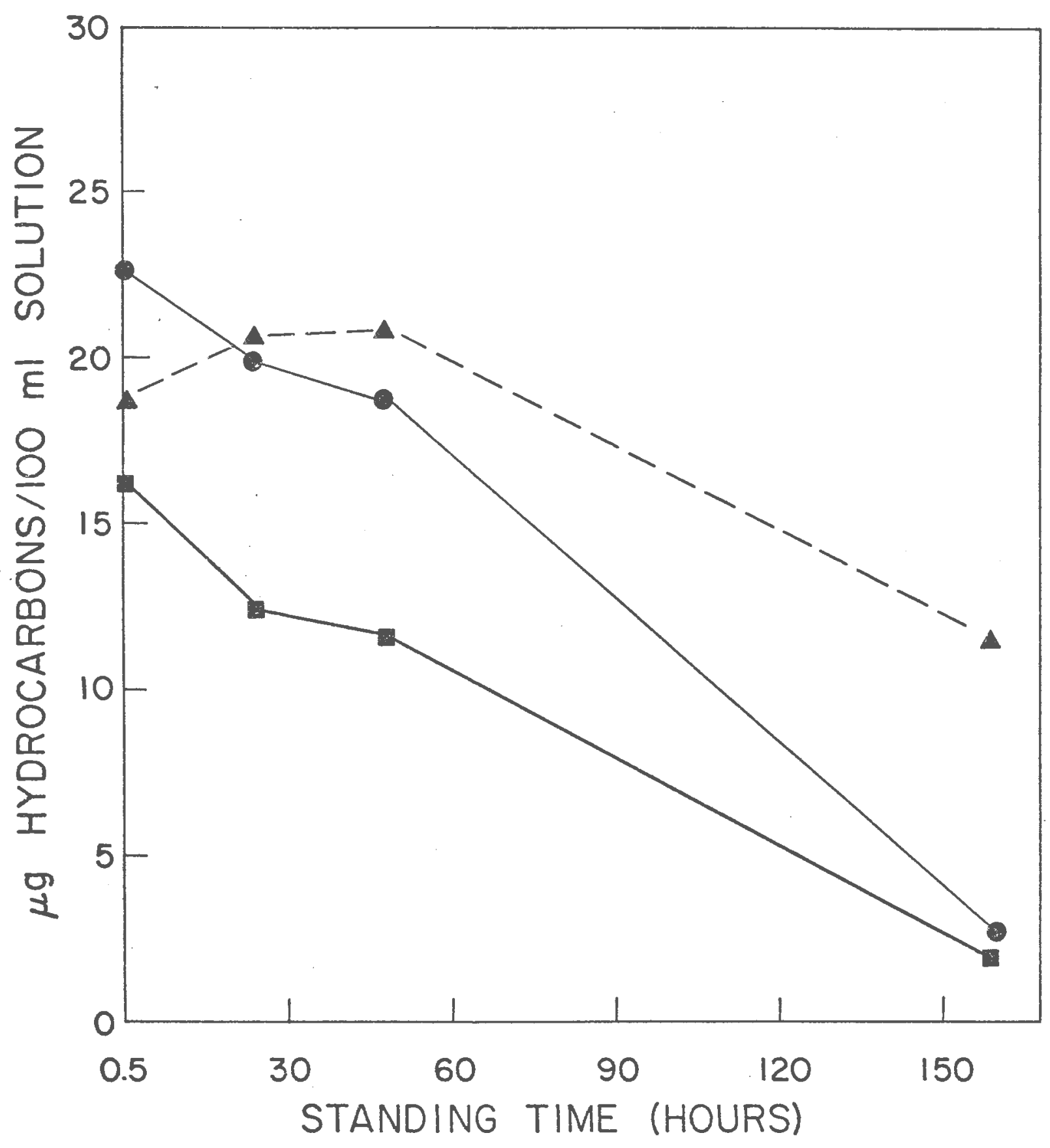


necessary to get sizeable quantities of hydrocarbon into solution so that large differences in solubility (tenfold) with different water samples (to be discussed below) might be observed. Therefore the 30 minute shaking and standing times achieved this goal.

Filtering by gravity gave n-alkane solubility values one-half of those for vacuum filtered samples. Phenanthrene passage was reduced to $80 \%$ of the vacuum filtered sample value.

The Effect of Dissolved Organic Carbon Removal

Table 2 summarizes the data on the solubility behavior of the n-alkanes, $n-C_{16}$ and $n-C_{20}$ and Table 3 for the isoprenoid hydrocarbon pristane, the aromatic hydrocarbon anthracene, the naphthenic hydrocarbon tetradecahydrophenanthrene (TDHP), and the aromatic ester dibutyl phthalate, that occurs when the D.O.C. content of the water is reduced. The solubility was not directly related to the absolute D.O.C. Ievels in the sea water probably due to fluctuations in the qualitative and quantitative distributions of natural organic components. However, the percentage decrease in solubility of the saturated hydrocarbons (hexadecane, eicosane, pristane, and TDHP) is a function of the percentage removal of the natural D.O.C. in Narragansett Bay water samples as illustrated in Fig 4. A 35-80\% removal of the D. O.C. results in a $75-96 \%$ reduction on hexadecane solubility. 
TABLE 2

THE EFFECT OF A REDUCTION IN THE

- DISSOLVED ORGANIC CARBON CONCENTRATION OF

SEA WATER ON HYDROCARBON SOLUBIIITY

\begin{tabular}{cccc}
\hline System & Dissolved Organic Hydrocarbon Solubility Test Solution \\
Number & $\begin{array}{c}\text { Carbon (D.0.C.) } \\
\text { (mg C/liter) }\end{array}$ & $\left(\mu-C_{16}: n-C_{20}:\right.$ Phen. & Type S\% pH.
\end{tabular}

$I$
a) 2.79
b) 1.33
$28.7:-\cdots \quad: 20.8 \quad$ NBW 287.8 $1.9: \cdots \quad 26.9$ NBW 287.8

2
a) 3.53
25.8
$8:-\infty: 23: 23$
$\begin{array}{lll}\text { NBW } & 28 & 8.2 \\ \text { NBW } & 28 & 8.2\end{array}$

3

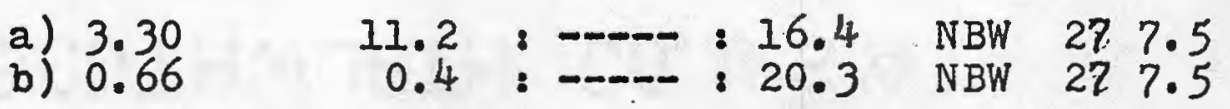

4

a) 3.60

25.5

$:-2: 14.6$

NBW $28 \quad 7.8$

a) 2.53
b) 0.67

23.

5

$4.4: 2.7: 17.4$

NBW $28 \quad 8.0$

6

a) 2.00

12.5

$:-$ \begin{tabular}{llll}
$\ldots$ & 19.0 & NBW & 28 \\
$\ldots$ & 8.2 \\
\hdashline-1 & NBW & 28 & 8.2
\end{tabular}

b) 0.48

0.1

12.6 :

$8.1: 15.9$

NBW $28 \quad 8.1$

7
a) 2.63

0.3

$0.1: 15.4$

NBW $28 \quad 8.1$

Hydrocarbon mixtures used: systems $1,2,3,4,6=200: 0: 40$ systems 5,7

a) = Narragansett Bay water, filtered

$=200: 200: 40$

b) = Narragansett Bay water, filtered and treated with activated charcoal

NBW = Narragansett Bay water 
FIGURE 4.--The solubility reduction of hexadecane upon removal of natural dissolved organic carbon with activated charcoal from Narragansett Bay water 


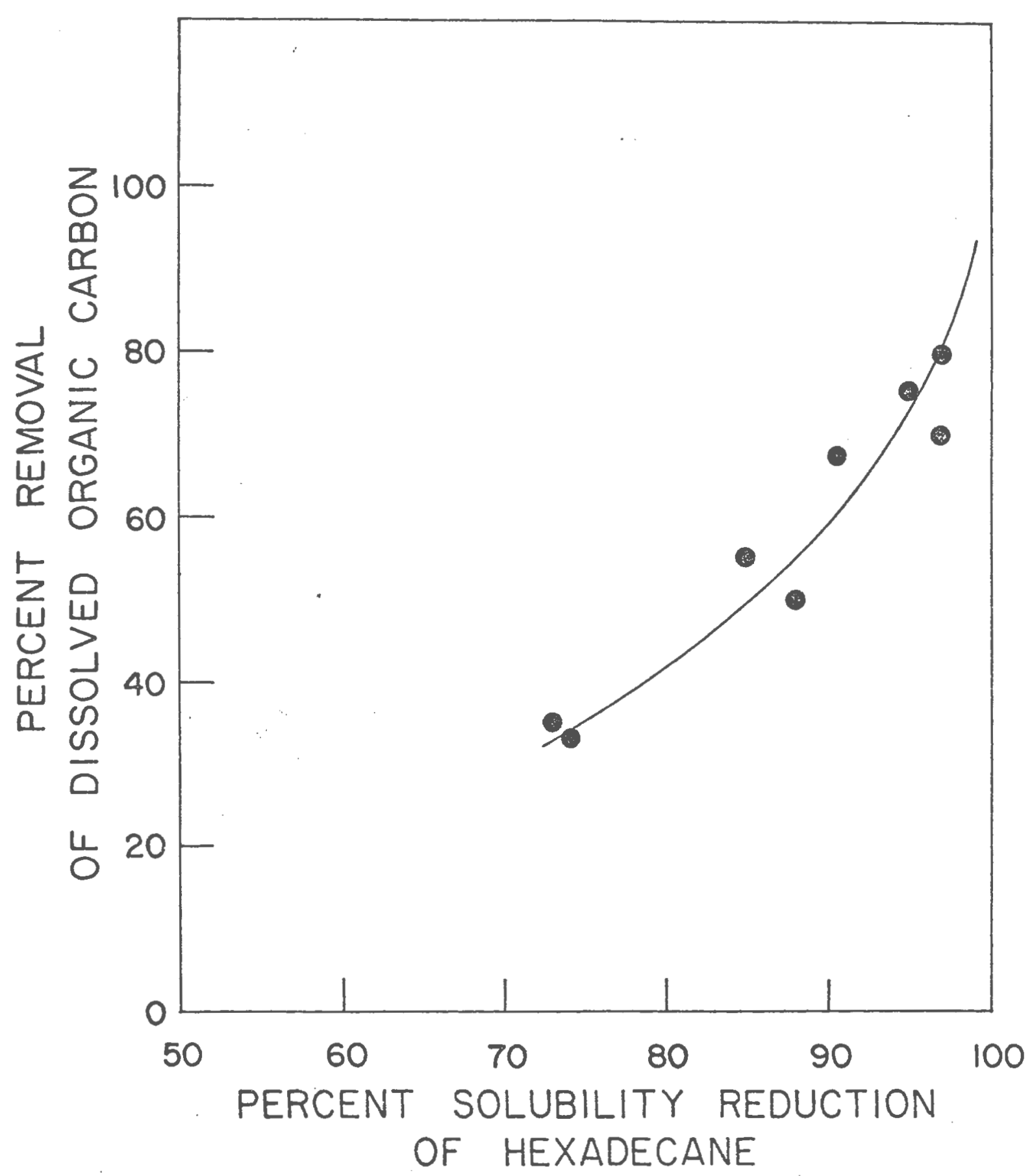


The solubility of hexadecane is reduced $75 \%$ with a $35 \%$ decrease in the D.O.C. thus suggesting that the most readily adsorbed organic materials, (e.g. the higher molecular weight organic matter which probably comprises the bulk of the organic material in sea water), are most responsible for a relatively large percentage of the hydrocarbon solubility. The effect of organic matter in the water on the solubility of phenanthrene (Table 2 and Table 3 ) as well as anthracene (Table 3 , system 2) and dibutyl phthalate (Table 3. system 1), a plasticizer and not generally prominent in petroleum, is readily apparent. The solubilities are unaffected by D.O.C. levels, thus indicating the negligible role that these compounds play in the dissolved organic matter-hydrocarbon interaction as previously indicated. This illustrates a difference between the binding action of humic substances in soils, where ogner and Schnitzer (1970b) found phthalates bound to humic acid, and where Matsuda and Schnitzer (1971) showed that soil fulvic acid could "complex" dialkyl phthalates and make them soluble in water. The organic matter in sea water does not affect the solubility of dialkyl phthalates in the context of this study.

on the other hand, the saturated phenanthrene compound, TDHP, (Table 3, system 4) appears to be solubilized by the D.O.M. in Narragansett Bay water. While not solubilized to the extent of the n-alkanes, its solubility was definitely, reduced upon the removal of the D.O.M. by activated charcoal. The isoprenoid hydrocarbon, pristane, (Table 3, system 


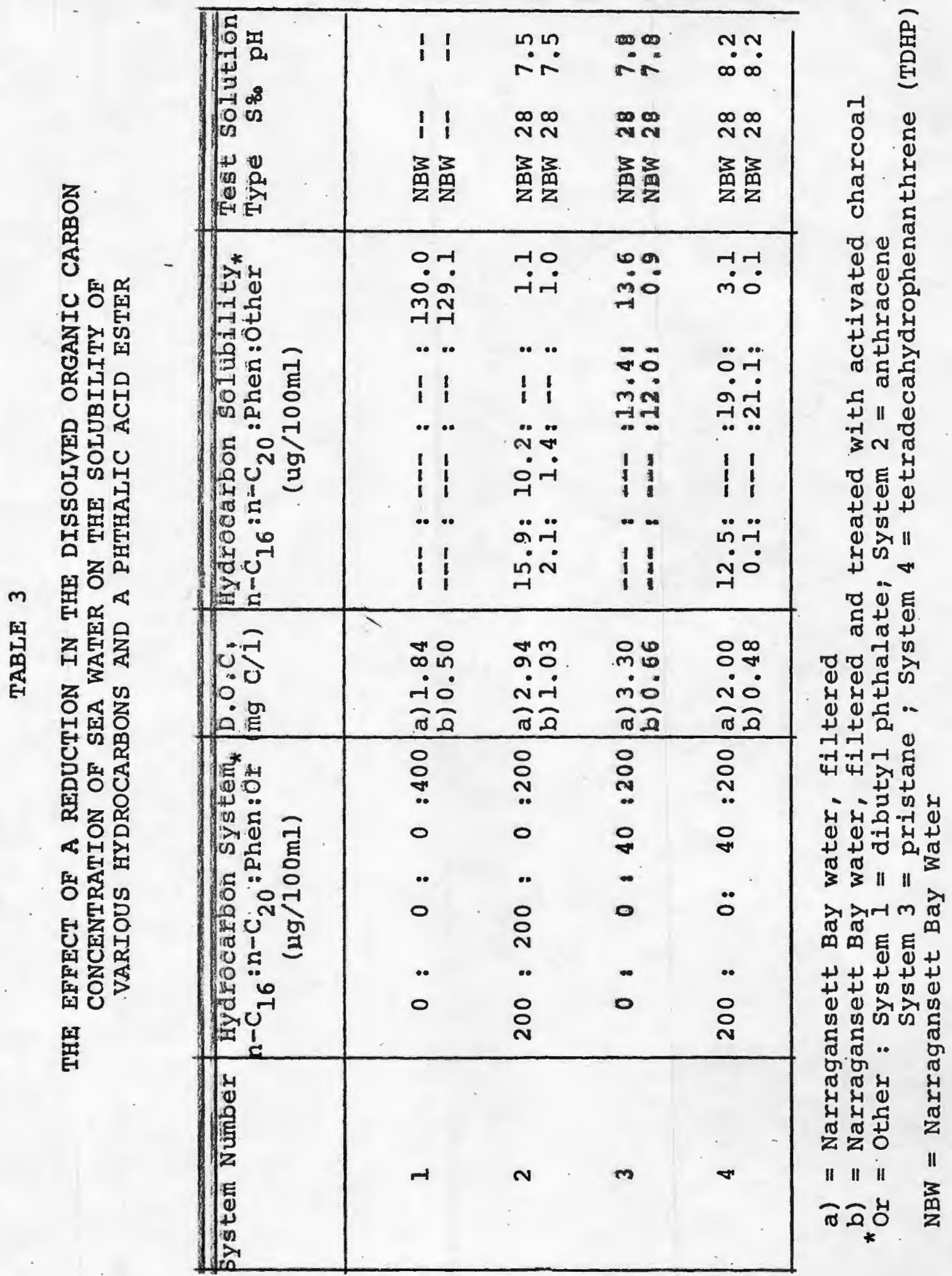


3) is solubilized to the same extent as is hexadecane, and upon removal of the D.O.M. from the media the solubilization of pristane fails to occur.

\section{Ultraviolet oxidation Study}

To insure that the effect of organic matter removal by adsorption on charcoal and the subsequent solubility reduction was in fact related to this removal, the organic matter in a sample of water from the Providence River, and in a saline solution containing fulvic acid was destroyed by U.V. oxidation. The salinities remained constant throughout the oxidation and the $\mathrm{pH}$ varied slightly - increased from 6.9 to 7.0 in the river sample and decreased from 7.5 to 6.8 in the fulvic acid solution. The $\mathrm{pH}$ was adjusted to initial values prior to solubility determination. The differences in solubility of the n-alkanes as seen in Table 4 (system 1 and 2) confirm the role of organic matter and specifically of fulvic acid (probably as sodium fulvate) in the solubilization process. As a control, sea water samples were heated to $70^{\circ} \mathrm{C}$ for 4 hours, cooled, and no change in hydrocarbon solubilities noticed between these samples and the unheated ones. Again, phenanthrene was not affected by the removal of dissolved organic matter. Furthermore the hydrocarbon solubility in the UV oxidized fulvic acid/saline water solution (system 2) is almost identical to the solubility in the original saline water (sýstem 3 ). 
TABLE 4

HYDROCARBON SOLUBIIITIES: ULTRAVIOIET OXIDATION AND FUIVIC ACID STUDIES

\begin{tabular}{|c|c|c|c|c|c|c|c|c|c|}
\hline $\begin{array}{l}\text { System } \\
\text { Number }\end{array}$ & $\begin{array}{l}\text { D.O.C. } \\
(\mathrm{mg} C / \mathrm{I})\end{array}$ & \multicolumn{5}{|c|}{$\begin{array}{l}\text { Hydrocarbon Solubility } \\
n-C_{16}: n-C_{20}: \text { Phen }\end{array}$} & \multirow{2}{*}{$\begin{array}{l}\begin{array}{l}\text { Test } \\
\text { Type }\end{array} \\
\text { PRW } \\
\text { PRW }\end{array}$} & \multicolumn{2}{|c|}{$\begin{array}{l}\text { Solution } \\
\text { S\% pH }\end{array}$} \\
\hline 1 & $\begin{array}{l}\text { a) } \\
\text { u) } \\
0.44\end{array}$ & $\begin{array}{r}32.3 \\
1.6\end{array}$ & 8 & $\begin{array}{r}19.2 \\
2.1\end{array}$ & $:$ & $\begin{array}{l}15.5 \\
17.0\end{array}$ & & $\begin{array}{l}20 \\
20\end{array}$ & $\begin{array}{l}6.9 \\
6.9\end{array}$ \\
\hline 2 & $\begin{array}{l}\text { a) } 17.50 \\
\text { u) } 1.00\end{array}$ & $\begin{array}{r}53.5 \\
0.6\end{array}$ & 8 & $\begin{array}{r}27.1 \\
0.1\end{array}$ & $:$ & $\begin{array}{l}22.0 \\
17.0\end{array}$ & $\begin{array}{l}\text { SFA } \\
\text { SFA }\end{array}$ & $\begin{array}{l}30 \\
30\end{array}$ & $\begin{array}{l}7.5 \\
7.5\end{array}$ \\
\hline 3 & $\begin{array}{l}0.20 \\
2.43\end{array}$ & $\begin{array}{l}0.8 \\
9.7\end{array}$ & $:$ & $\begin{array}{l}0.0 \\
6.4\end{array}$ & $:$ & $\begin{array}{l}20.7 \\
17.0\end{array}$ & $\begin{array}{l}\text { SAI } \\
\text { SINT }\end{array}$ & $\begin{array}{l}30 \\
30\end{array}$ & $\begin{array}{l}7.2 \\
7.2\end{array}$ \\
\hline 4 & 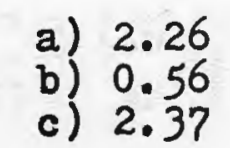 & $\begin{array}{r}16.3 \\
0.3 \\
20.4\end{array}$ & $:$ & $\overline{--\infty}$ & $:$ & $\begin{array}{l}20.7 \\
20.1 \\
18.7\end{array}$ & $\begin{array}{l}\text { NBW } \\
\text { NBW } \\
\text { NBW }\end{array}$ & $\begin{array}{l}30 \\
30 \\
30\end{array}$ & $\begin{array}{l}7.6 \\
7.6 \\
7.6\end{array}$ \\
\hline 5 & 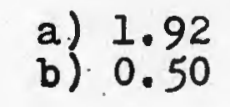 & $\begin{array}{r}14.3 \\
5.0\end{array}$ & $:$ & $\begin{array}{l}6.6 \\
3.4\end{array}$ & $:$ & $\begin{array}{l}19.9 \\
19.3\end{array}$ & $\begin{array}{l}\text { SFA } \\
\text { SFA }\end{array}$ & $\begin{array}{l}30 \\
30\end{array}$ & $\begin{array}{l}7.9 \\
7.9\end{array}$ \\
\hline 6 & $\begin{array}{l}0.75 \\
3.33\end{array}$ & $\begin{array}{r}7.9 \\
58.1\end{array}$ & $:$ & $\begin{array}{r}5.2 \\
33.2\end{array}$ & $:$ & $\begin{array}{l}20.6 \\
22.6\end{array}$ & $\begin{array}{l}\text { SAI } \\
\text { SFA }\end{array}$ & $\begin{array}{l}30 \\
30\end{array}$ & $\begin{array}{l}8.2 \\
8.2\end{array}$ \\
\hline 7 & $\begin{array}{l}\text { a) } 2.63 \\
\text { b) } 1.18 \\
\text { e) } 2.04\end{array}$ & $\begin{array}{l}12.6 \\
0.3 \\
\operatorname{tr}\end{array}$ & $:$ & $\begin{array}{l}8.9 \\
\operatorname{tr} \\
\operatorname{tr}\end{array}$ & $:$ & $\begin{array}{l}15.9 \\
15.4 \\
17.6\end{array}$ & $\begin{array}{l}\text { NBW } \\
\text { NBW } \\
\text { NBW }\end{array}$ & $\begin{array}{l}28 \\
28 \\
28\end{array}$ & $\begin{array}{l}8.1 \\
8.1 \\
8.1\end{array}$ \\
\hline 8 & $\begin{array}{l}\text { a) } 0.16 \\
\text { f) } 3.53\end{array}$ & $\begin{array}{r}2.3 \\
36.7\end{array}$ & $:$ & $\begin{array}{r}5.0 \\
33.4\end{array}$ & $:$ & $\begin{array}{l}17.6 \\
18.7\end{array}$ & $\begin{array}{l}\text { SAI } \\
\text { SHA }\end{array}$ & $\begin{array}{l}30 \\
30\end{array}$ & $\begin{array}{l}8.0 \\
8.0\end{array}$ \\
\hline
\end{tabular}

Hydrocarbon systems: $1,2,3,5,6,7,8,=200: 200: 40$

a) = water sample, filtered

b) = water sample, treated with activated charcoal

c) = charcoal treated water, sediment fulvic acid added

e) = water sample, filtered, charcoal treated, petroleum ether/sea water extract added

f) = water sample, sediment humic acid added

u) = water sample, ultraviolet oxidation treatment

NBW = Narragansett Bay water $; \mathrm{PRW}=$ Providence River water SFA = fulvic acid/saline water solution $;$ SAI = saline water

SINT = saline water plus raterial from $\mathrm{CHCl}_{3} / \mathrm{H}_{2} \mathrm{O}$ interface
$\mathrm{SHA}=$ humic acid/saline water solution 
The Effect of the Readdition of Fulvic

Acid from Several Sources

The loss of solubility of the n-alkanes upon dissolved organic carbon removal from natural sea water is reversed by addition of a concentrated sediment fulvic acid stock solution. The fulvic acid solution ( $360 \mathrm{mg}$ D.0.C./I) which was added to the organic depleted water to levels approximating initial D.O.C. content of the sea water $(0.5 \mathrm{ml}$ added to $99.5 \mathrm{ml}$ organic depleted water) reenhanced the solubility of $\mathrm{n}-\mathrm{C}_{16}$ (Table 4, system 4). Further addition of fulvic acid to a saline water test solution increases the solubility linearly (Fig. 5). Actually there is a minimum concentration of fulvic acid needed (greater than $0 \%$ fulvic acid but less than or equal to $0.5 \%$ ) above which solubilization occurs. This explains the break in the curve between $0 \%$ and $0.5 \%$ fulvic acid in Fig 5 . In all readdition experiments the $\mathrm{pH}$ and salinity of the test solution before and after D. O.C. reduction by activated charcoal, and after fulvic acid readdition were adjusted to original values. It was thought that an increase in solubility might be observed if the fulvic acid was allowed to "age" in the water before hydrocarbon addition, (Meyers, 1972) but no further increase was noted in a 24 hour "aging" period. When a solution of fulvic acid plus organic free saline solution was treated with activated charcoal, the n-alkane solubility again decreased markedly (Table 4, system 5).

The solubilizing properties of fulvic acid isolated from a muck soil (a gift from Dr. G.T. Felbeck Jr.) were 


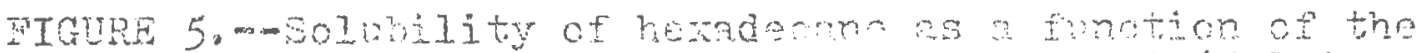

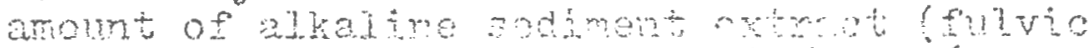

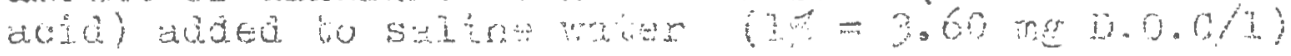




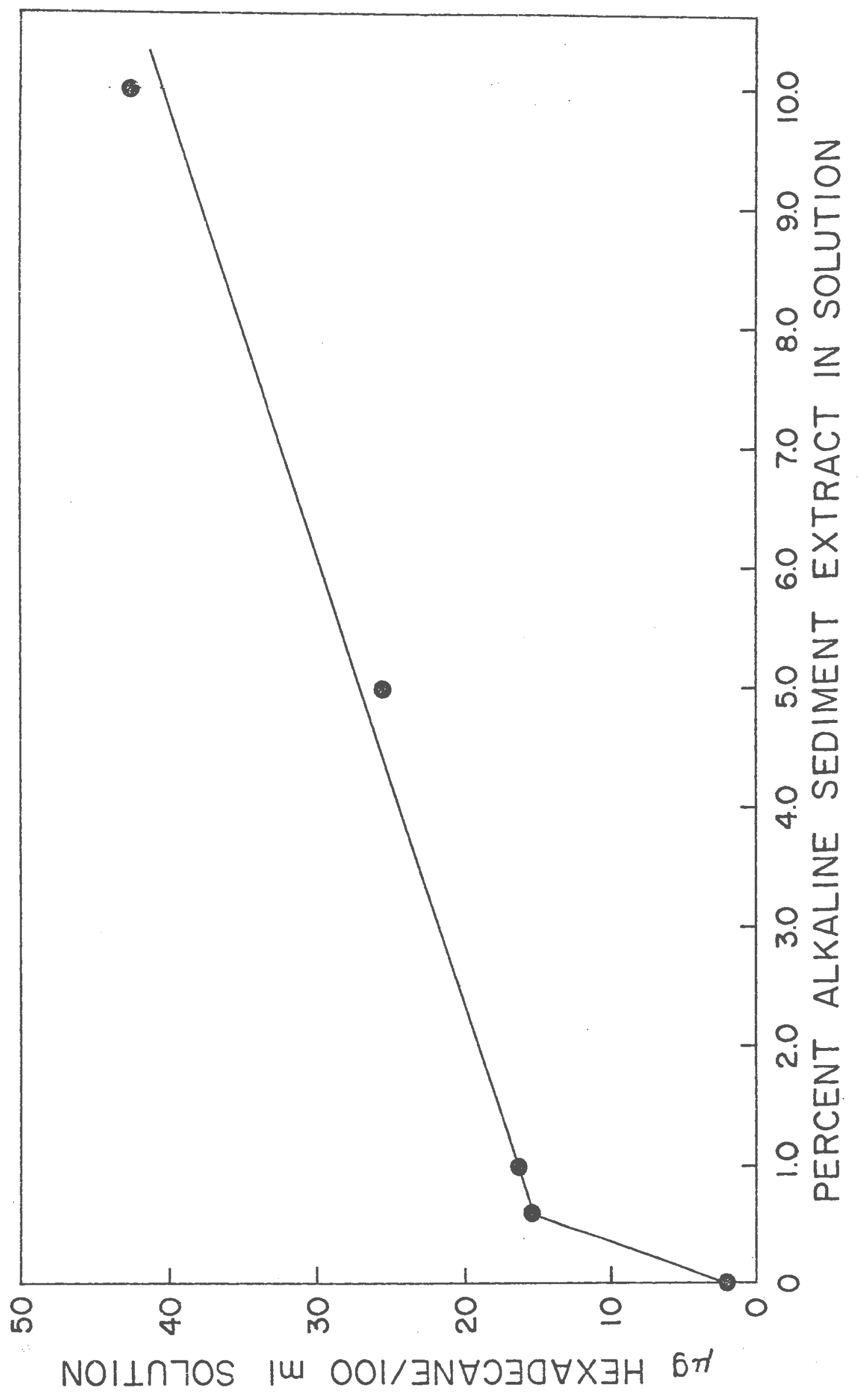


examined (Table 4, system 6). It can be seen that this fulvic acid sample was more effective on a per carbon weight basis in solubilizing the n-alkanes. For example, Figure 5. indicates that to achieve comparable hexadecane solubility for the sediment fulvic acid, a 10-15\% solution containing 36-54 mg D.O.C./I must be used. It is difficult to compare the two fulvic acid stock solutions directly owing to their different sources. Also the sediment material was crudely extracted, not purified as the muck soil fulvic acid was and may contain substantial amounts of non-humic carbon. However; the quantity of non-humic carbon can not account for the discrepancy between 3.33 and $36-54 \mathrm{mg}$ D.0.C./1. Therefore from this scanty evidence it may be hypothesized that the structural characteristics of the soil fulvic acid are sufficiently different from those of the sedimentary material to cause a large difference in solubilization behavior. On a per carbon weight basis, the solubilization properties of sediment fulvic acid, organic matter isolated at a chloroform/water interface (system 3) and D.O.M. in sea water are more closely related, perhaps indicating structural similarity.

The solubilizing properties of another fraction of humic material were investigated. (Table 4, system 8 ). This humic acid, isolated from the same sediment sample as the sediment fulvic acid discussed above, when added to a saline solution solubilized the n-alkanes. The extent of solubilization on a per carbon weight basis is somewhat greater than 
the sea water organic matter. However, it is difficult to compare humic acid's solubilizing properties to that of the organic matter from various sources. Furthermore, humic acid would not be expected to be as representative of the D.0.M. in sea water as fulvic acid owing to its lower water solubility caused by fewer functional groups on the molecule relative to fulvic acid as well as a higher molecular weight. (Schnitzer and-Khan, 1973)

Another method of increasing the solubility of the nalkanes in sea: water was to extract a marine sediment with sea water. The sediment used was the same as that extracted by $\mathrm{NaOH}$ in the preceding experiment. Twenty grams of sediment were blended with Narragansett Bay water $(200 \mathrm{ml})$ in a Waring Blender for one minute and the mixture filtered through a Gelman A filter. This extraction increased the D.0.C. in the water four times $(2.32$ to $10.2 \mathrm{mg} \mathrm{C} / 1)$, with a simultaneous increase in n-alkane solubility of 3.3 times for $n-C_{16}$ and 4.1 times for $n-C_{20}$. This laboratory method for increasing hydrocarbon solubility has its natural analog in areas where strong bottom currents occur, where turbidity currents are present, where dredging operations are in progress or where coastal storms cause sediment resuspension. Further evidence confirming the role of organic macromolecules in the solubilization of hydrocarbons was obtained by adding the alkaline $(0.5 \mathrm{~N} \mathrm{NaOH})$ soluble material isolated at a chloroform-sea water interface (Khaylov, 1968) to saline solution. This material was obtained by extracting 20 
liters of sea water with $500 \mathrm{ml}$ chloroform. The interface was isolated, the chloroform evaporated and the residue dissolved in sodium hydroxide, and an aliquot used in this experiment. As seen in Table 4, system 3, the n-alkane solubility increased over 10 times when the interfacial material was added to the test media. The substitution of material soluble in the chloroform phase for the interfacial material produced no increase in hydrocarbon solubility, thus eliminating lipoid material from consideration as the "active fraction" in sea water. To further investigate the role of the lipoidal material in sea water in the solubilization process, a $100 \mathrm{ml}$ sea water sample was thoroughly extracted (three times) with petroleum ether and the residue from this extract added to an identical sea water sample $(100 \mathrm{ml})$ from which the organic material had been removed by activated charcoal. Even though a substantial amount of organic carbon is added to the charcoal treated water, no hydrocarbon solubility enhancement is seen (Table 4, system 7). Essentially the petroleum ether extract adds 0.86 mg $\mathrm{C} / 1$ or $32 \%$ of the original D.O.C. content back into the water sample. It appears that it is the remaining $68 \%$, the non-lipoid fraction, which is responsible for the solubilization process. Specifically this suggests that fatty acids and other lipoidal material do not; at sea water concentration contribute to the solubilization of hydrocarbons. 
Hydrocarbon Solubility in Open Ocean Waters

The solubility of the basic hydrocarbion system was determined on one sample of Sargasso Sea water collected on $\mathrm{R} / \mathrm{V}$ Trident cruise TR 137, from Bermuda to Narragansett, R.I.= in June 1973. The sample was collected from a rubber raft approximately $500 \mathrm{~m}$ upwind of Trident at a location of $33^{\circ} 54.7^{\prime} \mathrm{N}, 65^{\circ} 41 . \cdot \mathrm{W}$. Solubility was determined on natural subsurface water (approx. $20 \mathrm{~cm}$ depth), a surface microlayer sample (top $150 \mu$ ) and on charcoal treated surface microlayer water. The surface microlayer was sampled with a polyethyiene screen using the technique of Garett (1965). Table 5 presents these results. The n-alkanes are ten times more soluble in the surface microlayer sample than they are in the subsurface water (system la vs. 2). Indeed, the nalkanes are not solubilized to any extent in the bulk of the sea water in this area, (system 2) if the samples studied here are representative of the horizontaliy well mixed, biologically unproductive area known as the Sargasso Sea. Treating the surface microlayer water with charcoal reduces the organic carbon and hence the hydrocarbon solubility. Also, it appears that the dissolved organic carbon is enriched 1.8 times in the microlayer which apparently results in the achievement of the critical micelle concentration in the microlayer (i.e. solubilization occurs). Williams (1967) found D.O.C. to be enriched 1.7-3.7 times in the surface microlayer relative to water at $15-20 \mathrm{~cm}$ depth. One can only speculate on the type of compounds which 
TABLE 5

SOLUBIIITY OF HYDROCARBONS IN NATURAL WATERSSOLUBILIZATION AT THE SURFACE MICROLAYER

\begin{tabular}{|c|c|c|c|}
\hline \multirow[t]{2}{*}{$\begin{array}{l}\text { System } \\
\text { Number }\end{array}$} & \multirow[t]{2}{*}{$(\mathrm{mg} \mathrm{c} / \mathrm{L})$} & $\begin{array}{l}\text { Hydrocarbon Solubility } \\
(\mu \mathrm{g} / 100 \mathrm{ml})\end{array}$ & \multirow[t]{2}{*}{$\begin{array}{l}\text { Test Solution } \\
\text { Type S\% pH }\end{array}$} \\
\hline & & $n-C_{16}: n-C_{20}:$ Phen & \\
\hline
\end{tabular}

\begin{tabular}{|c|c|c|c|c|c|c|c|c|}
\hline 1 & a) $\begin{array}{l}1.50 \\
\text { b) } 0.30\end{array}$ & $\begin{array}{l}8.9 \\
0.9\end{array}$ & $:$ & $\begin{array}{l}7.5 \\
0.5\end{array}$ & $\begin{array}{l}13.4 \\
: 13.5\end{array}$ & $\begin{array}{l}\text { SSA } \\
\text { CSA }\end{array}$ & $\begin{array}{l}34 \\
34\end{array}$ & $\begin{array}{l}8.3 \\
8.3\end{array}$ \\
\hline & 0.88 & 0.3 & 8 & 0.3 & .12 .6 & SSB & 34 & 8.3 \\
\hline & $\begin{array}{l}5.05 \\
4.41\end{array}$ & $\begin{array}{l}53.0 \\
45.8\end{array}$ & 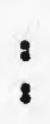 & $\begin{array}{l}33.4 \\
35.4\end{array}$ & $\begin{array}{l}21.8 \\
18.4\end{array}$ & $\begin{array}{l}\text { PIA } \\
\text { PIB }\end{array}$ & $\begin{array}{l}4 \\
5\end{array}$ & $\begin{array}{l}7.8 \\
7.8\end{array}$ \\
\hline & $\begin{array}{l}4.10 \\
2.78\end{array}$ & $\begin{array}{l}39.2 \\
34.7\end{array}$ & $:$ & $\begin{array}{l}22.3 \\
25.7\end{array}$ & $\begin{array}{l}19.1 \\
20.9\end{array}$ & $\begin{array}{l}\text { P2A } \\
\text { P2B }\end{array}$ & $\begin{array}{l}9 \\
9\end{array}$ & \\
\hline
\end{tabular}

a) = water sample, filtered

b) = water sample, filtered and treated with charcoal

SSA = Sargasso Sea water, surface microlayer

SSB = Sargasso Sea water, subsurface

CSA = Sargasso Sea water, surface microlayer, charcoal treated

PIA = Pettaquamscutt River water, sample 1, surface microlayer PIB = Pettaquamscutt River water, sample l, subsurface P2A = Pettaquamscutt River water, sample 2, surface microlayer P2B = Pettaquamscutt River water, sample 2, subsurface Hydrocarbon mixtures: systems $1,2,3,4,=200: 200: 40$ 
are enriched at the surface and which promote solubilization. However, one possibility is that they are surface-active humic-like compounds. The only similar study involving the nature of enrichment of organic carbon at the surface microlayer as it relates to hydrocarbon solubility in natural waters was performed using samples from the Pettaquamscutt River in Rhode Island (Boehm, unpublished data). In this study the dissolved organic carbon was enriched 1.1-1.5 times at the surface. However, solubilization of the hydrocarbon system was not limited to the microlayer, but was equal in surface and subsurface waters (Table 5, systems 3 and 4). The Pettaquamscutt River abounds in terrestrially leached humic material (the high solubility values reflect this - Table 5) and apparently either these humic materials are not enriched at the surface or are enriched negligibly compared to the high concentrations throughout the body of the river.

The data indicate again that the n-alkanes act identically to each other and that the aromatic hydrocarbon, phenanthrene, is not influenced by the dissolved organic matter.

The Effect of Filter Pore Size on Hydrocarbon Solubility

Peake and Hodgson (1967) investigated the physical distribution of hydrocarbons in distilled water using various sized Millipore filters. A similar study was 
undertaken here using Providence River water and Millipore filters of rated pore sizes of $0.22,0.45,0.80$, and 3.0 microns and comparing the amounts of n-hexadecane hydrocarbon passing these cellulose-acetate filters with the amount passing the Whatman GF/C glass fiber filter. All cellulose-acetate filters retained more hydrocarbons than did the glass fiber filter, thus extending Quinn and Meyers' (1971) results for fatty acids to hydrocarbons. The cellulose-acetate filter, Millipore HA $(0.45 \mu)$, allowed $0.5 \mu \mathrm{g}$ of hexadecane to pass while the $0.5 \mu$ glass fiber filter allowed the passage of $30.4 \mu \mathrm{g}$ of hexadecane. It may not be valid to directly compare the glass fiber and Millipore filter results because recently it was determined (Sheldon, 1972) that the Millipore filters retained particles much smaller than the stated pore size.

The linear nature of the plot in Fig. 6 supports the concept of micelle solubilized hydrocarbons. The micelles appear to be of non-uniform size as indicated by a linear decrease in the amount of solubilized $n-c_{16}$ seen in Fig. 6. If the micelles were of a specified size, rather than some average size, a break in the graph at this specific size might be expected. As can be seen in Fig. 6, there does not appear to be any break in the graph. If there was a break at this point, indicating a micelle size of approximately $0.5 \mu$ "diameter", this would agree with Baker's (1967) estimate of the size of what he thought to be hydrocarbon micelles. However, he did not consider humic micelles 
FIGURE 6.--The relationship of hexadecane solubility in Providence River water $\left(\mathrm{Sal}=20^{\circ} / 00, \mathrm{pH}=6.8\right.$, D.O.C. $=6.86 \mathrm{mg} \mathrm{C} / \mathrm{I}$ ) to cellulose acetate filter pore size 


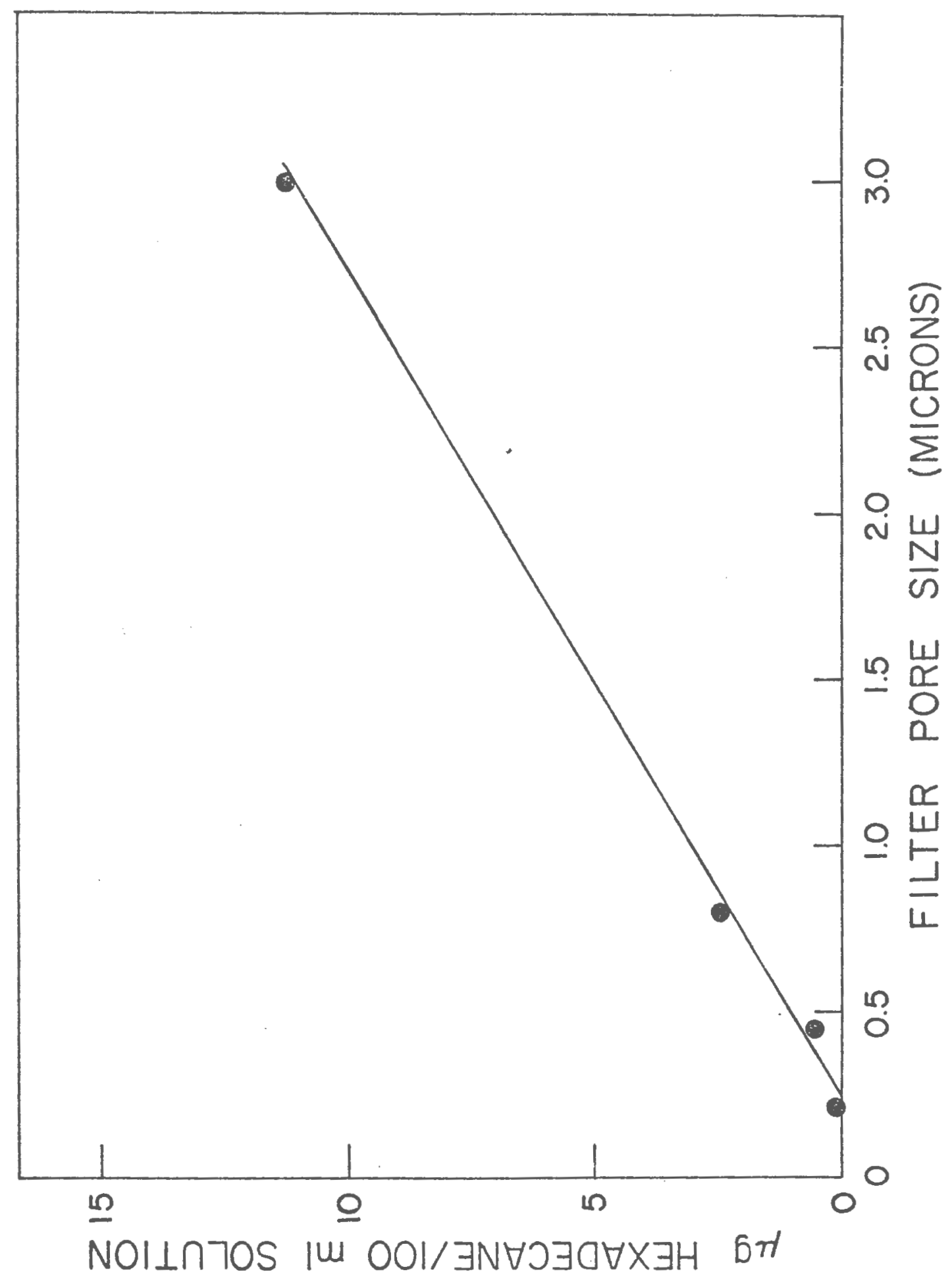


similar to those in this study.

Comparison of the data on the passage of $n-C_{20}$ through the 3.0 micron cellarlose acetate filter with that of Peake and Hodgson yields remarkably similar values $-0.07 \mathrm{mg} / \mathrm{l}$ and $0.08 \mathrm{mg} / \mathrm{I}$ respectively. However, due to radical differences in experimental technique - amount of hydrocarbon added, time of shaking and standing, type of aqueous media tested (salinity, pH, D.O.C.) filtration technique, etc. - direct comparison of this data is not advised. The structure, composition and mode of formation of micelles in Peake and Hodgson's secondary system (hydrocarbon and water) can not be related to the tertiary system (water, hydrocarbon, dissolved humic-type surfactants) in this study.

\section{The Effect of Salinity}

The close association of humic materials and inorganic species is well known (Schnitzer and Khan, 1973). An understanding of the interaction of dissolved salts and humic compounds is essential in order to understand solubilization phenomena in sea water. Hair and Basset (1973) have discussed the possibility that salinity influences the solubility of humic acids in estuaries. Kalle (1966) showed by spectrophotometric measurements that the quantity of "Gelbstoffe" decreases with increasing distance from the coast. The influence of salinity on the test solution's solubilization properties is shown in Fig. 7. These curves, 
FIGURE 7.--Hydrocarbon solubility as a function of salinity

- Hexadecane - fulvic acid/saline water solution ( $3.6 \mathrm{mg}$ D.0.C./I)

- Hexadecane - saline water solution

A Phenanthrene - fulvic acid/saline water solution ( $3.6 \mathrm{mg}$ D.0.C./I) 


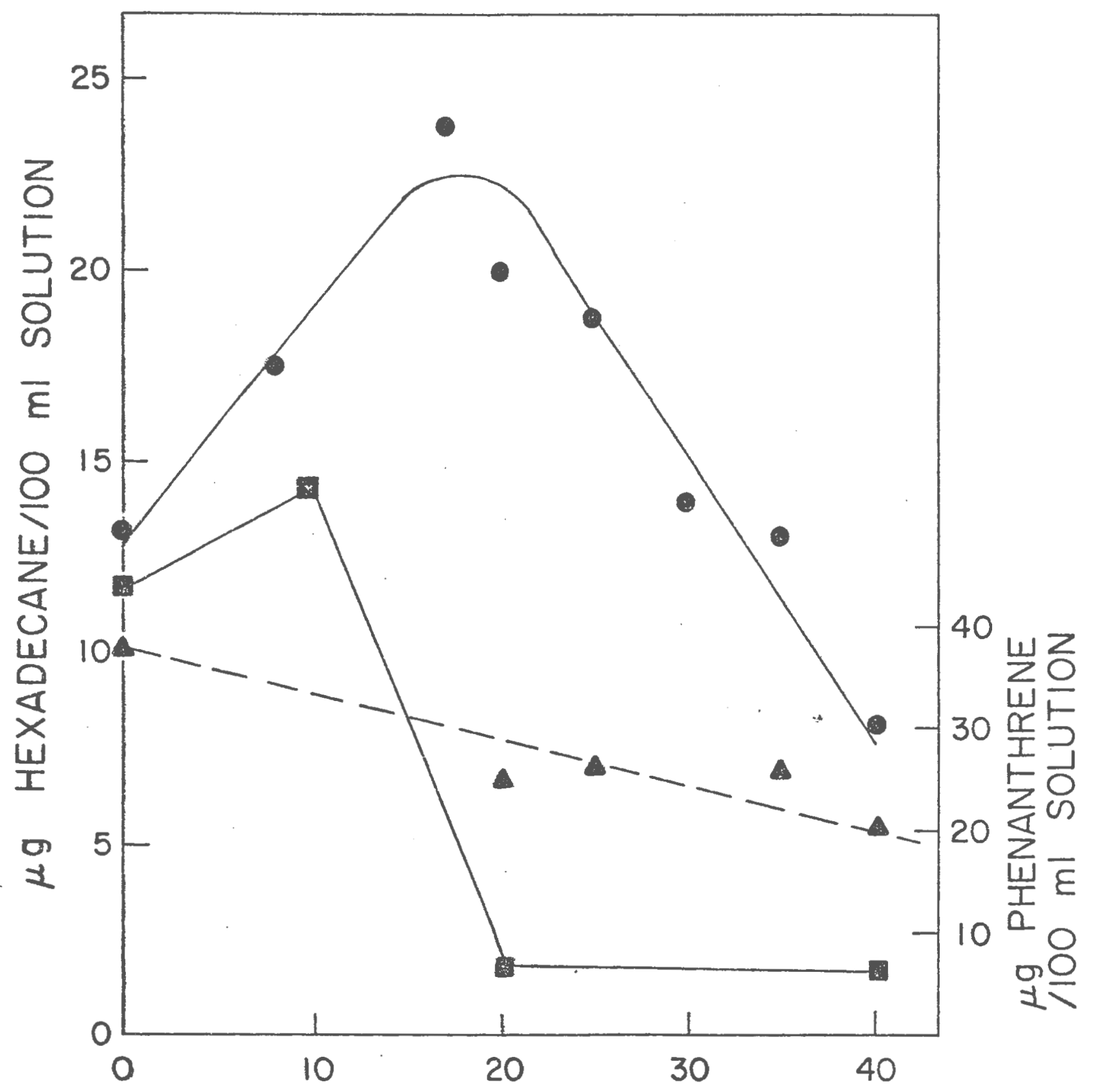

SALINITY (PARTS PER THOUSAND NaCl) 
which were quite reproducible, indicate that for a fulvic acid/saline water solution (D.O.C. $=3.6 \mathrm{mg}$ (arbon $/ I$ ), of $\mathrm{pH}=7.5$ at a salinity of approximately $17 \%$, (ionic strength $=0.3 \mathrm{~m})$, the solubilization potential of the test solution for $\mathrm{n}-\mathrm{C}_{16}$ is at a maximum. As the $\mathrm{NaCl}$ content increases beyond this point, the amount of hydrocarbon solubilized decreases linearly. A definite "salting in" trend is seen from $0 \%$ to $17 \%$. One of the curious findings of this study was that in distilled water the addition of fulvic acid had a very small solubilizing effect - (approximately a 5-8\% increase). Apparently the presence of a threshold concentration of ionic species is a prerequisite for the solubilization of the hydrocarbons by humic material. The existence of counter-ions (gegenions) associated with micellar structures is well known (Elworthy et al. 1968) and thus it appears that for solubilization to occur these ionically stabilized humic micelles must be available.

Humic solutions can be considered to be true solutions of dissociated macromolecules (macro-ions) or as negative hydrophobic colloids. Ong and Bisque (1968) studied one of the properties generally attributed to these colloids - coagulation (precipitation) by different electrolytes. They found that coagulation effectiveness decreased in the order of trisdismonovalent ions. For monovalent ions the order of increasing effectiveness in coagulation is $\mathrm{Li}<\mathrm{Na}<\mathrm{K}$ and for divalent ions, $\mathrm{Mg}<\mathrm{Ca}$. The authors also investigated the coagulation effectiveness of some anions and the effective- 
ness decreased in the order of $\mathrm{SO}_{4} \overline{\overline{ }} \mathrm{NO}_{3}{ }^{-}>\mathrm{Cl}^{-}$. These series depend on how close the hydrated ions can approach the humic surface, the larger ions having smaller hydration radii. Ong and Bisque showed that humic compounds in solution can actually be considered as colloids.

This coagulation theory is based on the double-layer theory which is valid for hydrophobic colloids. Humic colloids are generally considered to be hydrophilic. However, hydrophilic colloids are transformed to hydrophobic ones according to the Fuoss effect (Fuoss and Cathers, 1949), which is outlined as follows:

1) the polyelectrolyte (humic compound) dissolves in water, the functional groups becoming dissociated,

2) the negatively charged functional groups mutually repel each other, the polyelectrolyte assuming a stretched configuration,

3) the addition of salts alters this behavior as the cations are paired with the negatively charged functional groups,

4) this results in a reduction in intramolecular repulsion and a coiling of the chain is favored.

5) the coiling causes expulsion of water of hydration, (a squeezing out of this water of hydration)

6) the humic macromolecules become less solvated hydrophobic colloids to which the coagulation theory applies.

It should be noted that the value of $17 \%$ as the solubilization maximum does not apply in sea water for the salinity effect is probably an ionic strength effect and the availability of divalent species in sea water shifts this curve. Such an expected shift was observed in the direction of lower salinity. The same shaped curve as for $n-c_{16}$ in Fig. 7 with an apparent maximum at $S=10 \%$ (ionic strength $=0.2 \mathrm{~m}$ ), decreasing linearly thereafter, was observed. This experiment utilized charcoal treated sea water which was 
diluted with distilled water to adjust the salinity (pH was constant at 8.0 ), and then added to fulvic acid giving a concentration of $9 \mathrm{mg} \mathrm{c} / \mathrm{l}$. These solutions were used to determine hydrocarbon solubility. The shift in this curve can be attributed to the increased coagulation effectiveness of the divalent and trivalent cations present in sea water relative to the effectiveness of $\mathrm{NaCl}$.

The apparent "salting out" effect of $n-C_{16}$ above 17 ppt in Fig. 7 may be partially due to the dehydration of the humic monomers, thus decreasing their polarity and increasing their tendency to aggregate and/or associate as large micelles (coagulation) which may not be able to pass the filter. It is well known that the addition of salts decreases the critical micelle concentration, CMC, (the surfactant concentration at which micelles begin to form) due to a reduction in intermolecular repulsion between polar head groups with a reduction in the amount of electrical work needed for micelle formation (Elworthy et al.,1968). The micellar size increases with the addition of salts as does the micellar weight. Presumably above $17 \%$ either "salting out" effects outweigh the increased driving force toward micelle formation, or the micellar size increases at the expense of surfactant dispersion, thus reducing the number of sites available for hydrocarbon solubilization as well as the number of micelles passing the filter. It appears that the phenanthrene solubility, which is independent of organic matter content and hence of micelle formation, decreases with increasing salt 
content, thus lending creedence to the former explanation without diminishing the importance of the latter. The salting out of $n-C_{16}$ observed may also be related to the increasing importance of non-ionic n-alkane aggregations, termed micelles by Baker (1967), which have an average size of $0.5 \mu$ and may be retained by the filter.

In Fig. 7 the solubility of $n-C_{16}$ first increases and then decreases in saline water without fulvic acid. The McDevit-Iong theory, (McDevit and Long, 1952) accounts for both salting-in and salting-out effects. This theory explains that the salt induced medium effects arise from the effect of the salt on the intermal pressure of the solvent. This is equivalent to a consideration of the energy required to create a "hole" for the non-electrolyte molecule. Apparently initial addition of electrolyte to water lowers this energy requirement with a subsequent addition (greater than 10\%) increasing this energy barrier.

\section{The Effect of $\mathrm{pH}$}

The passage of n-alkanes through the glass fiber filter is clearly related to the pH of the aqueous media (Fig 8). The salinity was held constant at $30 \%$. However, the role of the humic material in this effect is clear only on the $\mathrm{pH}$ range 6 to 9. The solubility of the n-alkanes is high and independent of the added fulvic acid at $\mathrm{pH}$ above 9.0 . However, in the $\mathrm{pH}$ range $6-9$, the presence of fulvic acid 
FIGURE 8.--Hydrocarbon solubility as a function of $\mathrm{pH}$

- Hexadecane-fulvic acid/saline water

- Hexadecane-saline water solution

$\triangle$ Eicosane-fulvic acid/saline water

$\triangle$ Eicosane-saline water solution 
66

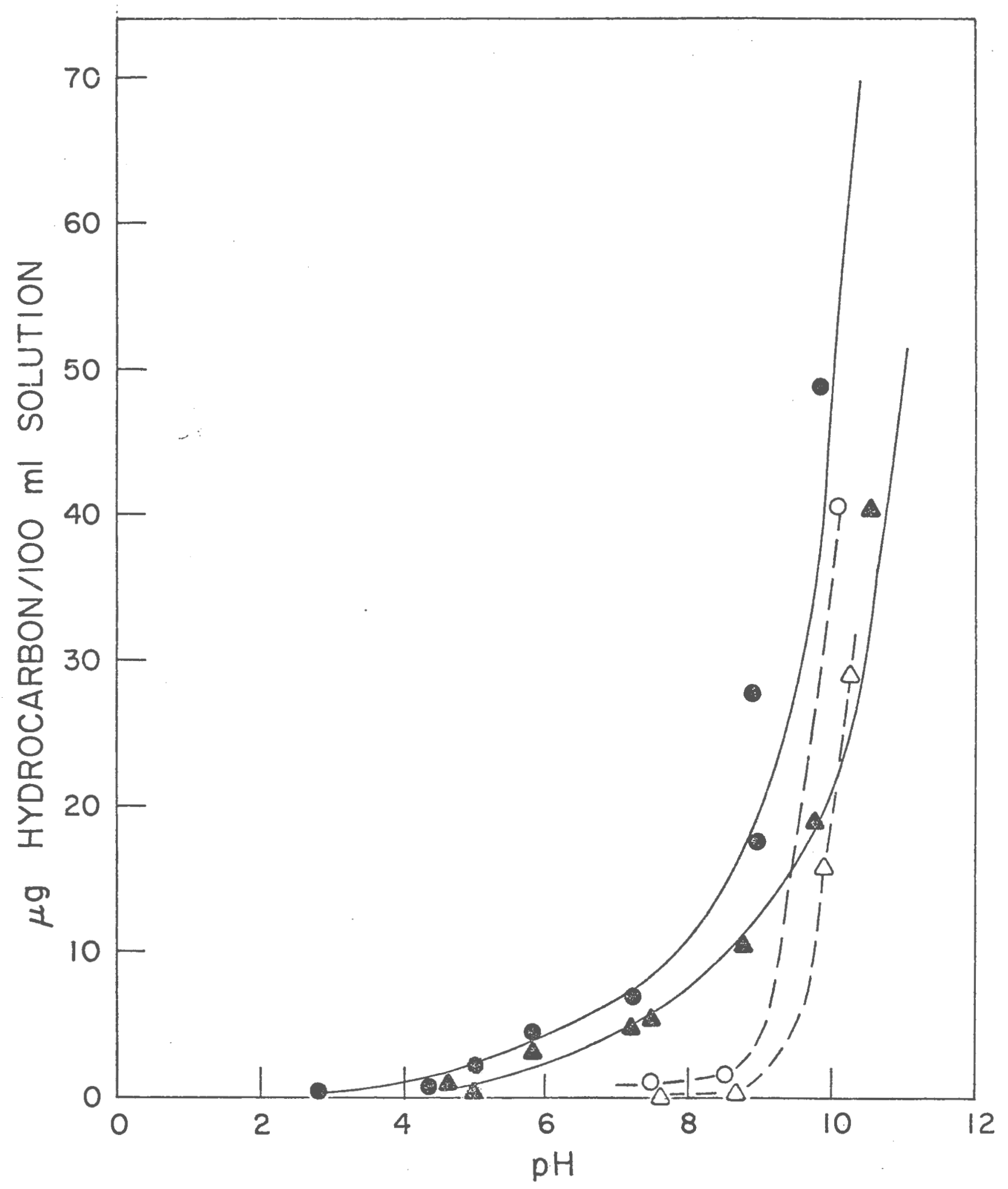


did enhance the solubility relative to saline solutions and the increase in solubility with increasing $\mathrm{pH}$ in this $\mathrm{pH}$ range was also related to the presence of the fulvic acid. The solubility of phenanthrene was unaffected by the pH of the media. Thus this pH effect above 9.0 is at present unexplained. It seems unlikely that the high $\mathrm{pH}$ has a direct effect on the aggregation or micelle formation of the nonpolar (uncharged) n-alkane molecules in the absence of surfactant molecules. If the size of n-alkane aggregates or micelles was dependent on the $\mathrm{pH}$, it seems certain that a charge reversal of the surface charge on the n-alkane micellar surface would explain the apparent dispersing phenomenon noted above a pH of 9.0. Baker (1967) has discussed such n-alkane "micelle" formation. Furthermore modification of the filter appears not to be occuring in light of the constancy of phenanthrene solubility. In the pH range 6-9, that which we are concerned with in the marine environment, the increasing solubility with increasing $\mathrm{pH}$ can be attributed to the increasing ionization of carboxyl groups, with a concomitant increase in the surface activity of the sodium fulvate and hence an increased tendency toward intermolecular and/or intramolecular micellization.

Flaig (1971) described the dependence of humic acid aggregation on the pH. He found that a sharp decrease in solution viscosity occurs at a $\mathrm{pH}$ lower than 3.5 resulting in the formation of humic micelles. The terminology "micelles" is misleading in this context and "aggregates" 
would be a better word to describe these clurips of humic material at low ph. In the context of the present investigation, micelle formation by humic compounds results in solubilization of non-polar solutes and can not be equated to the clumping that Flaig describes. He showed that a marked dispersion of humic acids occurs at a pH of 8.0 . It may be that at a pH greater than 9 or 10 , solubilization of nonpolar hydrocarbons by humic micelles may become insignificant as compared to a general dispersing of hydrocarbons as well as humic monomers. Furthermore, increasing the $\mathrm{pH}$ of distilled water had no: apparent effect on the n-alkane and aromatic solubilities. Increasing the $\mathrm{pH}$ had a profound effect only in the presence of ionic species. Peake and Hodgson (1966) found that $\mathrm{NaHCO}_{3}$ added to distilled water (1 gram/liter) increased n-alkane accommodation three to four times. According to the findings in this study this increase must be due to the existence of ionic species from $\mathrm{NaHCO}_{3}$ in conjunction with the pH effect. (This concentration of $\mathrm{NaHCO}_{3}$ raises the $\mathrm{pH}$ of distilled water from 6.5 to 8.3$)$.

The Influence of a Sewage Effluent

Solubility determination on water from the Providence River, which flows into the Narragansett Bay estuary, resulted in values two to four times the "normal" values for $n-C_{16}$ found in the Bay proper (Table 6, system 1 and 3). The 
TABLE 6

HYDROCARBON SOLUBILITY IN A SEWAGE EFFLUENT AND IN PROVIDENCE RIVER WATER SAMPLES

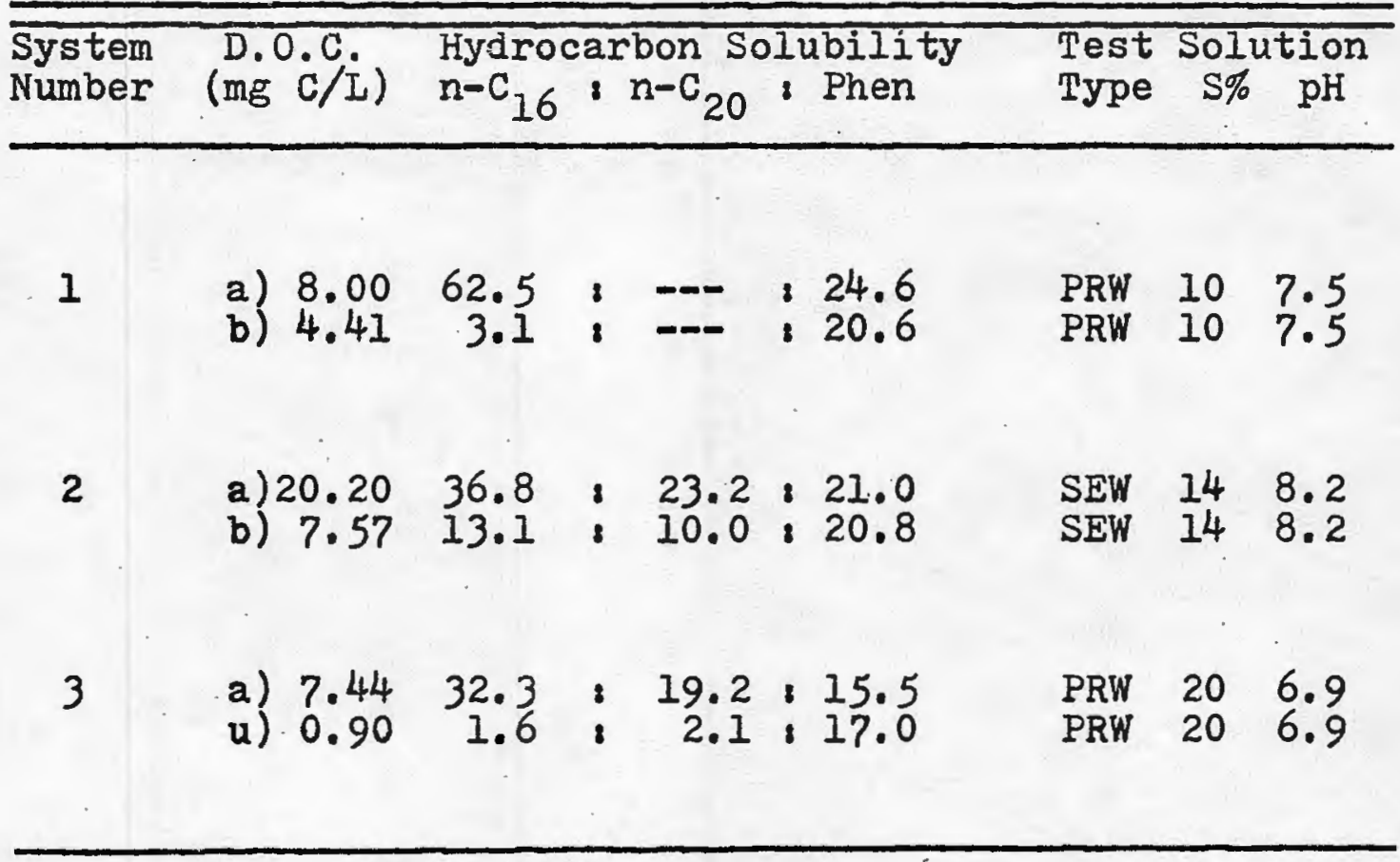

Hydrocarbon systems $: 1=200: 0,40 ; 2,3=200,200: 40$

a) water sample, filtered

b) water sample, filtered and charcoal treated

u) water sample, filtered and treated by ultaviolet oxidation

PRW = Providence River water

SEW = Sewage effluent, Field's Point sewage treatment plant 
river water which was sampled 100 meters downstream of the Fields Point Sewage effluent contained 6.9 to $8.4 \mathrm{mg}$ D.0.C. /iter at the times sampled compared. to 2 to $4 \mathrm{mg}$ D.O.C./ liter within the Bay. The effluent itself contained 31.5 mg D.O.C./Iiter.

If the solutions of some river water samples taken near the sewage effluent and hydrocarbons were allowed to stand prior to filtration for greater than 15 minutes, a chalky beige precipitate appeared. It was determined that this precipitate scavenged the solubilized hydrocarbons from solution. After one half hour the hydrocarbon solubility was reduced to trace quantities. This was never observed in Narragansett Bay water or in fulvic acid/saline water solutions. This precipitate was probably related to a high level of humic-like material in the river which upon precipitation removed the hydrocarbons from solution by sorption and perhaps by trapping in internal molecular void spaces. The phenanthrene solubility actually increased with time in spite of the precipitation, a finding which may be attributed to its amphiphilic nature, and which is consistent with previous findings that the presence of humic material had no effect on its solubility.

The large hydrocarbon solubilities in the river water, (Table 6, system 1) may be due to the interaction of the river water with the sewage effluent or merely to terrestrial humic leachings. The increase in n-alkane solubilities in these river samples can not be attributed solely to their 
lower salinities (see Figure 7). That is to say, the difference in the solubilizing potential of solutions of equal D.O.C. concentrations but with different salinities can be $10-15 \mu \mathrm{g} / 100 \mathrm{ml}$ at the most, according to Fig.7. Thus the effect of salinity does not account for the high solubility in system 1 .

The solubility of the hydrocarbon system was determined in a sewage effluent sample. The results for system 2 in Table 6 indicate that removal of some of the organic matter in the sample results in a decrease in solubility. This decrease is not as dramatic as seen in other water samples, (Table 2). Although the D.O.C. is reduced $63 \%$ by activated charcoal, the remaining $37 \%(7.6 \mathrm{mg} \mathrm{c} / 1)$ may contain surfactants capable of solubilizing the hydrocarbons. Indeed, the composition of the sewage effluent (Farrington and Quinn, 1973b) is unlike Narragansett Bay water and a greater reduction in D.O.C. levels may be required before a large reduction in solubility is seen. Also, considering the high organic content of the effluent $(20.2 \mathrm{mg} \mathrm{c} / \mathrm{l})$ the solubility is relatively low. Because of their relatively high concentration $(0.7-43 \mathrm{mg} / \mathrm{l}$, Farringtion and Quinn, 1973b) fatty acid salts (soaps) may play a role in the solubilization process in the sewage effluent. However, if humiclike materials are produced by microbial action in treatment plants as Rebhun and Manka (1971) maintain, then these materials can solubilize hydrocarbons. Presumably they can also then remove them from the water column by precipitation 
as shown previously. This implies that the transport of hydrocarbons from contaminated municipal waterways or from sewage effluents themselves and subsequent deposition in benthic environments somewhere in the upper estuary, due to perhaps $\mathrm{pH}$ and salinity gradients, may be a very significant phenomenon.

The solubility in the effluent itself compares well with that of the Providence River sample of salinity $=20 \%$, (Table 6; system 2 vs. system 3), but not to that sample of salinity $=10 \%$ (system 1 ). The agreement between systems 2 and 3 may be coincidental because the D.O.C. of the effluent is higher and the salinity lower than that of the river sample. Perhaps the D.O.C. and salinity trends oppose each other; the increased solubilization potential due to a greater amount of D.O.C. being cancelled out by a lower salinity. Fig. 7 indicates that for solutions containing organic material (top curve) the solubilizing potential reaches a maximum at approximately $17-20 \%$. Thus a solution with a salinity of $10 \%$, or for that matter $25 \%$, will solubilize a lesser amount of n-alkanes than will one of salinity $=20 \%$. The large solubility in system I may be due to the sample being high in surfactant concentration (soaps, humics, etc.)

A preliminary investigation on the effect of mixing sewage effluent with Narragansett Bay water showed that there is an almost linear decrease in n-alkane solubility. in mixtures ranging from pure sewage effluent to pure Narra- 
gansett Bay water (e.g. hexadecane solubility decreases Iinearly from $28 \mu \mathrm{g} / 100 \mathrm{mI}$ to $10.2 \mu \mathrm{g} / 100 \mathrm{ml})$. This decrease is linear with respect to decreasing D.O.C. as well as increasing salinity. Therefore at present no conclusion can be made on the nature of the driving force of this effect (i.e. salinity or D.O.C.).

Samples from the same sewage effluent studied here were show by Farrington and Quinn (1973b) to contain large amounts of hydrocarbons, $(2.4$ to $16.2 \mathrm{mg} / I)$ indicating that the failure of the treatment operations to remove this material may be due to solubilization of the hydrocarbons by the dissolved organic matter in the effluent. The findings in this study suggest that an adjustment of the salinity in the treatment plant's flocculation procedure could decrease hydrocarbon solubility and possibly decrease the quantity of hydrocarbons in the sewage effluent.

The Effect of Fulvic Acid and Natural Dissolved organic Matter on the Solubility of Fuel 0il

The presence of fulvic acid in the test solution (3.72 mg D.O.C./I) increased the total hydrocarbon solubility of No. 2 fuel oil (b.r. $n-C_{12}$ to $n-c_{22}$ ) from $244 \mu \mathrm{g} / 1$ in saline water $(30 \% \mathrm{NaCl})$ to $542 \mu \mathrm{g} / \mathrm{I}$ in fulvic acid/ saline water (Table 7). However, it is more interesting to examine the details of this increase. Figure 9 shows the chromatograms for, $\mathbb{A}$ - the fuel oil, added to saline water, mixed and extracted with petroleum ether, B - the hydrocar- 
FTCURE 9,-a-sorbbility of number 2 fund oil

GIS chrometograms.

A. No. 2 fuch oil orrol (i.s, mjod with seine wetor and extracted wite gelroleum ether m no filsmation

B. No, 2 rel ail colvole in rulvic acidl saline weter solution $(3,72$ ms a, o.c./1)

c. $\mathrm{No}_{2} 2$ fuel ojl soluble in saine water 


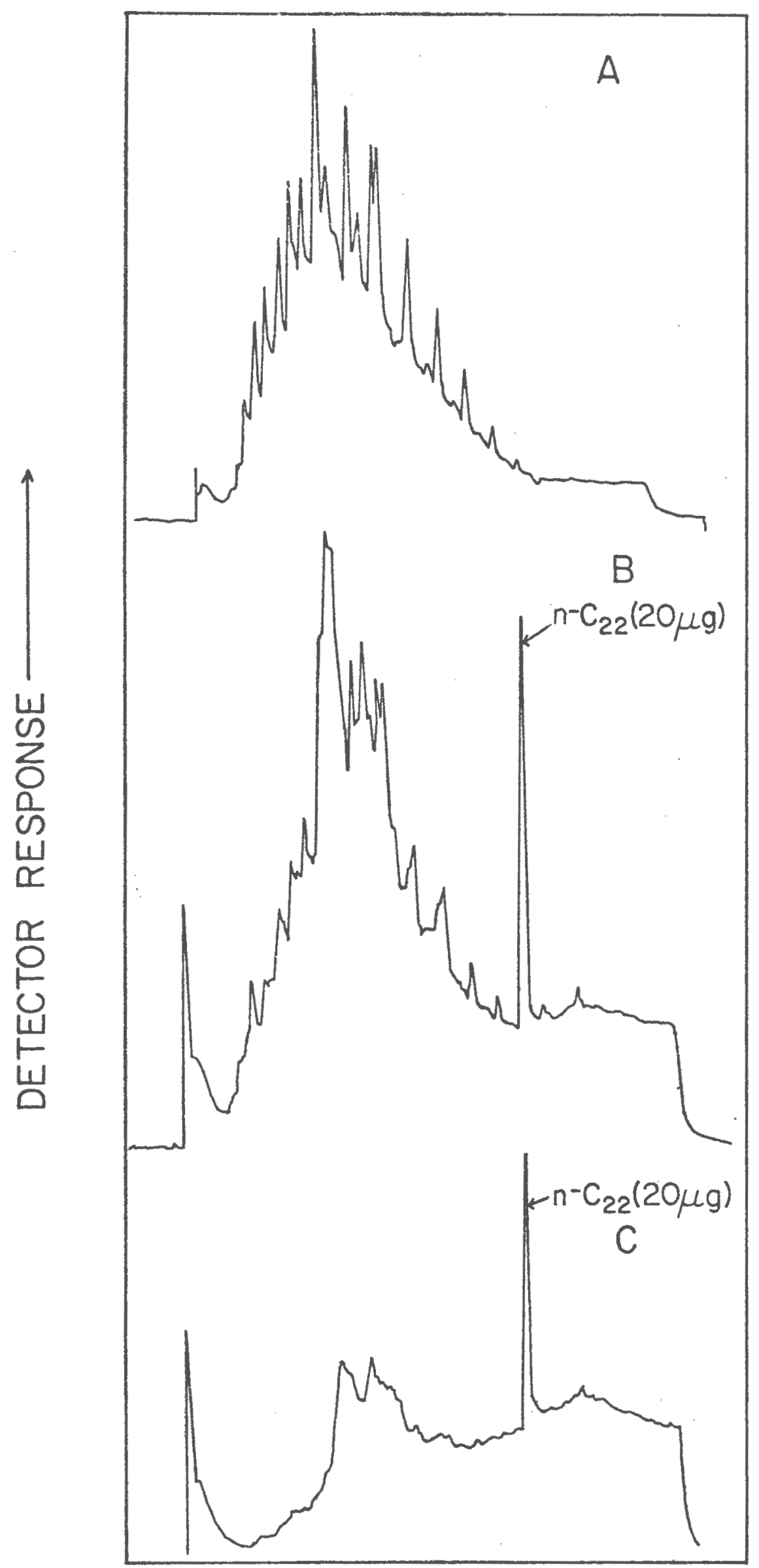

75 
bons soluble in fulvic acid/saline water solution, and C the hydrocarbons soluble in saline water alone. Chromatogram B illustrates that these soluble hydrocarbons retain basic fuel oil characteristics seen in $\mathrm{A}, \mathrm{i} . \mathrm{e}$. the unresolved complex mixture of aromatic and naphthenic hydrocarbons measured as a broad envelope, plus the resolved components, measured as peaks, which are mostly n-alkanes, branched chain alkanes and isoprenoid hydrocarbons. Chromatogram. B represents $397 \mu \mathrm{g}$ of the unresolved mixture in addition to $145 \mathrm{\mu g}$ of the peak producing hydrocarbons. Chromatogram $\mathrm{C}$ illustrates that the hydrocarbons soluble in saline water without fulvic acid lack distinct features of the alkanes and isoprenoids and are essentially all unresolved features $(244 \mu \mathrm{g})$. Note that not only is chromatogram $C$ lacking in peaks but the size of the unresolved complex mixture envelope has decreased from 397 to $244 \mu \mathrm{g}$. This difference is probably not due to a change in aromatic hydrocarbon solubility, as it has been previously shown that natural organic matter in the test solution has no effect on phenanthrene or anthracene solubility. Therefore, the difference may be attributed to naphthenic hydrocarbons (saturated cyclic and branched cyclic hydrocarbons) or to any other unresolved components, the solubility of which are affected by the presence of fulvic acid. It is interesting to note that the $n$-alkane, $n-C_{17}$, and the isoprenoid hydrocarbon, pristane, are both solubilized to the same extent. As seen in chromatogram $B$ the ratio of the peak heights of 
these hydrocarbons is the same in chromatograms $A$ and $B$.

Similar experiments were performed using Narragansett Bay water as the solubilizing media. The data in Table ? indicates in all experiments a reduction in the total quantity of fuel oil solubilized occurs when the dissolved organic matter is removed from the water. Systems 3 and 4 were spiked with docosane $\left(n-C_{20}\right)$, in the quantity of $1 \mathrm{mg}$ $\mathrm{n}-\mathrm{C}_{20}$ per $15 \mathrm{mg}$ No. 2 fuel oil, to follow the behavior of the n-alkanes. all cases, the chromatograms show a clear reduction in resalved components indicating that the removal of the D.O.M. frome the water affects the n-alkanes and branched chain altranes dramatically. The unresolved envelope decreased in area probably indicating a reduction in the solubility of naphthenic hydrocarbons.

The presence of the spiked $n-C_{20}$ and its solubilization decreases the solubility of the fuel oil (system 2 vs. systems 3 and 4). Eicosane itself is approximately fifteen times less soluble in this fuel oil $/ \mathrm{n}-\mathrm{C}_{20}$ mixture than it is in the simple natrocarbon systems of Table 2. This is most likely due tolits 15:I dilution in the spiked fuel oil mixture. These results are in complete accord with previous findings on indivadual aliphatic, isoprenoid, naphthenic, and aromatic hydrocarbon systems, and extend them to include fuel oil, a complex multicomponent hydrocarbon system. 
TABLE ?

SOLUBILITY OF FUEL OIL IN FULVIC ACID SOLUTIONS AND IN NARRAGANSETT BAY WATER

\begin{tabular}{|c|c|c|c|c|c|c|}
\hline $\begin{array}{l}\text { System } \\
\text { Number }\end{array}$ & $\begin{array}{c}\mathrm{D.0. \textrm {C }} \\
(\mathrm{mg} \mathrm{c} / \mathrm{I})\end{array}$ & $\begin{array}{l}\text { Total Fuel oil } \\
\text { Solubility } \\
(\mu g / l)\end{array}$ & $\begin{array}{c}n-c_{20} \\
\text { Solublity } \\
(\mu g / 1)\end{array}$ & $\begin{array}{c}\text { Test } \\
\text { Type }\end{array}$ & $\begin{array}{l}\text { Solut } \\
\text { S\%. }\end{array}$ & $\begin{array}{c}\text { ion } \\
\text { pH }\end{array}$ \\
\hline 1 & $\begin{array}{l}0.20 \\
3.72\end{array}$ & $\begin{array}{l}244 \\
542\end{array}$ & -- & $\begin{array}{l}\text { SAI } \\
\text { SFA }\end{array}$ & $\begin{array}{l}30 \\
30\end{array}$ & $\begin{array}{l}8.0 \\
8.0\end{array}$ \\
\hline 2 & $\begin{array}{l}\text { a) } 1.97 \\
\text { b) } 0.53\end{array}$ & $\begin{array}{l}459 \\
310\end{array}$ & $-\infty$ & $\begin{array}{l}\text { NBW } \\
\text { NBW }\end{array}$ & $\begin{array}{l}28 \\
28\end{array}$ & $\begin{array}{l}7.8 \\
7.8\end{array}$ \\
\hline 3 & $\begin{array}{l}\text { a) } 3.25 \\
\text { b) } 2.15\end{array}$ & $\begin{array}{r}199 \\
95\end{array}$ & $\begin{array}{l}9.6 \\
5.0\end{array}$ & $\begin{array}{l}\text { NBW } \\
\text { NBW }\end{array}$ & $\begin{array}{l}28 \\
28\end{array}$ & $\begin{array}{l}8.1 \\
8.1\end{array}$ \\
\hline 4 & $\begin{array}{l}\text { a) } 2.53 \\
\text { b) } 0.67\end{array}$ & $\begin{array}{r}151 \\
95\end{array}$ & $\begin{array}{r}10.0 \\
2.7\end{array}$ & $\begin{array}{l}\text { NBW } \\
\text { NBW }\end{array}$ & $\begin{array}{l}28 . \\
28\end{array}$ & $\begin{array}{l}8.0 \\
8.0\end{array}$ \\
\hline
\end{tabular}

a) water sample, filtered

b) water sample, filtered and treated with activated charcoal

NBW = Narragansett Bay water

SAL = saline water $(\mathrm{NaCl})$

$\mathrm{SFA}=$ saline water plus sediment extracted fulvic acid 
Micelle Formation and Solubilization

by Surfactant Humic Material

From the data presented it appears that the naturally occurring dissolyed organic matter in sea water is intimately involved in the mobilization of petroleum-like hydrocarbons (n-alkanes, isoprenoids, and naphthenic compounds). An overall appraisal of the data leads to the conclusion that the surface-active nature of the D.0.M. accounts for this phenomenon which has been referred to as solubilization. The solubilized hydrocarbons actually exist in a semicolloidal or miceilar state formed by interactions of humiclike monomers in solution.

The various experiments illustrate the process' dependence on the existence of ionic species and therefore the possible existence on n-alkane, non-ionic micelles as proposed by Baker (1967) does not alone account for the solubilization phenomena at the $\mathrm{pH}$ and salinity of normal sea water and under our experimental conditions.

Piret et al. (1960) found that the critical micelle concentration (CMC), of peat derived humic acid in $0.26 \mathrm{M}$ $\mathrm{NaCl}$, was approximately 18 grams/liter. This is an extremely large amount of organic material in terms of estuarine and open ocean water with dissolved organic carbon values in the 0.3-20 mg D.0.C./1 range (Riley and Chester, 1971). We might not expect micelle formation and hydrocarbon solubilization to occur in sea water if it weren't for a few basic features of micelle chemistry. (Elsworthy et al., 1968; Winsor, $1956 \mathrm{a}, \mathrm{b})$ : 
1) The addition of solubilizates (the hydrocarbon species being solubilized) lowers the CMC.

2) The addition of added electrolytes, increasing the salinity to sea water levels, decreases the CMC due to a decrease in the number of surfactant molecules present as monomers, with a corresponding increase in the number associated as micelles.

3) Slightly soluble substances can undergo large increases in solubility when added to surfactant solutions containing a sub-critical micellar concentration of surfactant. That is, the CHC does not have to be attained in some situations to achieve solubilization. This phenomenon is termed co-micellization.

The intermolecular and intramolecular association of humate monomers in the presence of charged species may be related to Van der Waals attractions, which at a certain ionic strength of the media, are at a maximum. An ionic double layer on the surface of the macromolecule comprised of charged gegenions and solvent molecules or clusters may be postulated (Rashid et al., 1972). The double layer is compressed with increasing ionic strength of the media and as this layer is compressed, Van der Waals attractions within and between monomers increase. Micelle formation, which requires an orientation of polar and non-polar molecular segments, is promoted and the hydrocarbons may be solubilized within the non-polar regions of the micelle. As the salinity increases beyond this point of maximum attraction, increased competition for water molecules, which participate in hydration of free charged species, may result in a disruption of the double layer or a charge reversal. The resulting effect is an increased electrostatic repulsion of surfactant monomers, causing a disruption of micellar structures and/or a salting out of hunic colloids. 
The increasing solubility with increasing $\mathrm{pH}$ in the range 6 to 9 may be attributed to increasing surface activity of humate molecules as the $\mathrm{pH}$ is raised. The increased passage of $n$-alkanes through the filter at elevated pH greater than 9 must be related to either an increase in $n$-alkane dispersion, possibly due to a charged adsorbed layer on the hydrocarbon surface or on the vessel walls, or to n-alkane "micelle" formation. In light of the fact that the increased n-alkane solubility at high $\mathrm{pH}$ is not observed unless ionic species are present, the former explanation is favored.

Thus far this presentation has not included the specifics of incorporation of the hydrocarbons into the suitable non-polar regions of the humic micelle. One can only speculate as to the conformation of humic macromolecules in solution. They may exist in a clathrate or caged structure (Degens, 1970; Schnitzer and Khan, 1973) in a spiral arrangement or in an open array. This clathrate may be made up of individual humic monomers or several monomers hydrogen bonded together through their functional groupings. Polar functional groups could be oriented outward. Within the non-polar regions, the hydrophobic hydrocarbons could be accommodated resulting in their solubilization. There is no evidence to refute the possibility of adsorption playing a role in the hydrocarbon-humic association. Adsorption on the outer surface of the humic molecule in close proximity to the polar solvent, water, would be energetically unfavorable. Adsorption on inner surfaces (i.e. on the boundary 
between non-polar regions of the humic molecule and intermal voids in the clathrate structure) is not conceptually different from micellar accommodation (i.e. incorporation into nonpolar regions of the micelle).

The mechanism of the adsorption of non-polar materials (DDT) to humic acid has been studied by Pierce et al. (1971) and Pierce (1973). A mechanism of capillary adsorption within pores in the humic polymer was proposed. This adsorption was seen to be a result of 1) hydrophobic bonding to lipoidal moieties within the humic structure, and 2) weak dipole and induced dipole interactions (e.g. pi bond interactions) between aromatic portions of DDT and the humic adsorbent.

In solution, humic and humic-like molecules must assume a configuration which is thermodynamically stable in water. The colloidal micellar structure in which polar and nonpolar segments of the humic molecules become "aligned" to fit into the structure of the water, is achieved. The presence of ionic species causing a coiling of the molecule has been shown to be a prerequisite for solubilization to occur. Thus, the concepts developed in this thesis explaining micellar solubilization of hydrocarbons are analogous to Pierce's (1973) findings, attributing humic acid adsorption of nonpolar pesticides to hydrophobic bonding. The question remains as to why the aromatic compounds studied are not:solubilized by humic-like surfactants. Gordon and Thorne (1967b) demonstrated that naphthalene was 
solubilized by the surface-active fatty acid salt, sodium decanoate, at concentrations above the CMC. In the present study phenanthrene was found to be equally soluble in all waters of the same salinity and $\mathrm{pH}$ regardless of the concentration of D.O.M. The high degree of unsaturation of the aromatic rings probably results in easier incorporation into the water structure, perhaps due to hydrogen bonding between water molecules and the aromatic hydrogen atoms.

The strikingly different solubilities of phenanthrene (m. $\mathrm{p}_{0}=101^{\circ} \mathrm{C}$ ) and anthracene (m. $\mathrm{p}_{0}=216^{\circ} \mathrm{C}$ ), the latter being ten to twenty times less soluble than the former, can be attributed to the slightly different position of the third benzene ring:

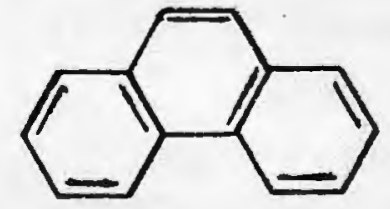

Phenanthrene

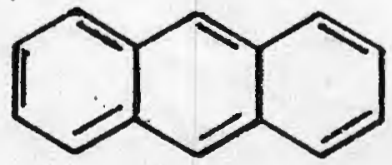

Anthracene

One might conclude, on the basis of the behavior of phenanthrene, that the polycyclic aromatic hydrocarbons are preferentially incorporated into the water structure and that humic micelles do not offer a thermodynamically "better" site for aromatic accommodation. However, the water solubility of anthracene is low. It might seem that in the case of anthracene, preferential incorporation into humic micelles would tend to occur as anthracene is not readily soluble in organic "free" saline water. However it is clear that the presence of D.O.M. in sea water has no effect on anthracene's 
(or phenanthrene's) solubility. Thus it may be concluded that the aromatic hydrocarbons, anthracene and phenanthrene, are excluded from incorporation into the humic micelles rather than being preferentially attracted to water. This exclusion may be due to a steric hindrance caused by the interaction of the pi electron clouds of the aromatic molecules with the aromatic segments of the humic molecule. The rigid planar conformation of the aromatic molecules in comparison to the flexible non-planar saturated cyclic compounds (e.g. TDHP) may be responsible for the exclusion of the former and the inclusion (accommodation) resulting in the solubilization of the latter. It appears that attractive pi bond interactions do not explain the behavior of the aromatic hydrocarbons toward humic molecules in solution as these hydrocarbons appear to be exeluded from the sites of solubilization rather than attracted.

Meyers (1972) found that the adsorption of anthracene to clay minerals was much greater than that of phenanthrene. His results are analogous to the solubility behavior of these compounds noted in this study.

It appears that Gordon and Thorne's (1967b) results for the micellar solubilization of an aromatic hydrocarbon by sodium decanoate (a structurally simple molecule) do not apply to the solubilization by the complex humic macromolecules.

This study has shown that surface-active, non-lipoidal, humic-like material in sea water and humic substances from a 
variety of other sources effectively solubilize hydrophobic material in sea water. Quinn and Meyers (unpublished data) have observed that fulvic acid in saline solutions and the indigenous organic matter in sea water can solubilize fatty acids. Further characterization of these solubilizers as to molecular weight ranges, and functional dependence on the solubilization process is needed and will serve as the basis of a Ph.D research project. 


\section{V-SUMMARY}

The solubilization of some petroleum hydrocarbons (n-alkanes, an isoprenoid and a naphthenic compound) by humic and humic-like organic matter from a variety of sources has been illustrated. The sources of this organic matter are: 1) the dissolved organic matter in sea water, 2) fulvic acid extracted from a marine sediment, 3) the organic matter extracted by sea water from a marine sediment, 4) the material isolated from sea water at a chloroform/sea water interface, 5) the organic matter in a municipal sewage effluent, 6) fulvic acid extracted from a muck soil, and, 7) humic acid extracted from a marine sediment. The solubilizing potential of the organic matter from sources 1 to 4 are most alike on a per carbon weight basis. The extent of solubilization depends on the concentration of the humiclike substances in the solubilizing medium.

The surface microlayer of a Sargasso Sea water sample was enriched in dissolved organic carbon relative to a subsurface sample. The former solubilized n-alkanes, while the latter sample exhibited no appreciable solubilizing power.

Number 2 fuel oil is solubilized by fulvic acid in a saline solution and was also shown to be more soluble in natural sea water than in charcoal treated sea water. In the absence of fulvic acid and natural dissolved organic 
matter, the solubility of the alkane and isoprenoid fractions of the oil is greatly reduced and the chromatographically unresolved fraction, consisting mainly of aromatic and naphthenic compounds, decreases in quantity.

The polycyclic aromatic hydrocarbons phenanthrene, anthracene, as well as dibutyl phthalate are not affected by this humic material (i.e. they are not solubilized).

The mode of solubilization is thought to occur by incorporation of the hydrocarbons into micellar structures formed by the surface-active humic and humic-like substances. The hydrocarbons are probably incorporated into the hydrophobic regions of the micelle. The formation and behavior of these colloidal micelles are strongly related to the $\mathrm{pH}$ and salinity (ionic strength) of the media.

The results of this work are discussed in terms of their important implications for:

1) the transport, dispersion and sedimentation of hydrophobic pollutants in estuaries and coastal areas,

2) the effect of municipal sewage effluents on the transport of these pollutants,

3) the migration and accumulation of petroleum source material,

4) the further study of marine organic macromolecules, using the experimental tools developed in this thesis. 


\section{VI-IIST OF REFERENCES}

Akiyama T. (1972) Chemical composition and molecular weight distribution of dissolved organic matter produced by bacterial degradation of green algae, Geochem. Jour. 6. 93-104

Armstrong F.A., Williams P.M., and Strickland J.D. (1966) Photooxidation of organic matter in sea water by ultraviolet radiation - analytical and other application. Nature 211, 481-483

Baker E.G. (1960) A hypothesis concerning the accumulation of sediment hydrocarbons to form crude oil, Geochim. Cosmochim. Acta 12, 303-317

Baker E,G. (1967) The evaluation of petroleum migration and accumulation, In Fundamental Aspects of Petroleum Geochemistry (edited by B. Nagy and U. Colombo) Elsevier

Boylan D.B. and Tripp B.W. (1971) Determination of hydrocarbons in sea water extracts of crude oil and crude oil fractions, Nature 230, 44-47

Degens E.T. (1970) Molecular nature of nitrogenous compounds in sea water and recent marine sediments, In Organic Matter in Natural Waters (edited by D.W. Hood), Institute of Harine Science, University of Alaska

Duursma E.D. (1965) The dissolved organic constituents of sea water. In Chemical Oceanography (edited by J.P. Riley and G. Skirrow), Academic Press, London

Elworthy P.H., Florence A.T., and Macfarlane C.B. (1968) Solubilization by Surface Active Agents, Chapman and Hall Itd.; Iondon

Farrington J.W. and Quinn J.G. (1973a) Petroleum hydrocarbons in Narmagansett Bay, Part $I$. Survey of hydrocarbons in sediments and clams, Estuarine and Coastal Marine Science. 1 ; 71-79

Farrington J.W. and Quinn J.G. (1973b) Petroleum hydrocarbons and fatty acids in wastewater effluents. J. Water Pol1. Cont. Fed. 45, 4, 704-711

Felbeck G.T. jr. (I97I) Chemical and biological characterization of humic matter, In Soil Biocheristry, Vol 2 (edited by A.D. Mclaren and J.J. Skujins) Marcel Dekker New York 
Flaig W. (1971) Some physical and chemical properties of humic substances as a basis of their characterization, In Advances in Organic Geochemistry, p. 49-67. Pergamon Press, Oxford-Braunschweig

Frank H.S, and Franks F. (1968) Structural approach to the solvent power of water for hydrocarbons; urea as a structure breaker, J. Chem. Phys. 48, 10, 4746-4757

Franks F. (1966) Solute-water interactions and the solubility behavior of long chain paraffin hydrocarbons, Nature 210, $87-88$

Fuoss R.M. and Cathers G.I. (1949) Polyelectrolytes: 3 , J. Polymer Sci. 4, 97-120

Garrett W.D. (1965) The collection of slick forming materials from the sea surface, Iimnol. 0ceanogr. 10, 602

Gordon J.E. and Thorne R.I. (1967a)-Salt effects on the activity coefficient of naphthalene in mixed aqueous electrolyte solutions. I. Mixtures of two salts, J. Phy. Chem. 21. 13, 4390-4399

Gordon J.E. and Thorne R.I. (196́7b) Salt effects on nonelectrolyte activity coefficients in mixed aqueous electrolyte solutions - II. Artificial and natural sea waters, Geochim. Cosmochim. Acta 31, 2433-2443

Hair M.E. and Bassett C.R. (1973) Dissolved and particulate humic acids in an east coast estuary, J. Estuarine and Coastal Marine Science, 1, 107-111

Kalle K. (1966) The problem of Gelbstoffe in the sea, In Marine Biology Annual Review, (edited by $\mathrm{H}$. Barnes) Vol. 4, George Allen and Unwin Ltd., London

Khailov K.M. and Burlakova Z.P. (1972) Release of dissolved organic matter by marine seaweeds and distribution of their total organic production to inshore communities, Limnol. Oceanogr. 14, 4, 521-527

Khan S.U. and Schnitzer. M. (1972) The retention of hydrophobic organic compounds by humic acid, Geochim. Cosmochim. Acta 36 . 745-754

Khaylov K.M. (1968) Dissolved organic macromolecules in sea water, Geochem. IntI. 5, 497-503

Koons C.B. (1973) Chemical composition: A control on the physical and chemical processes acting on petroleum in the marine environment, unpublished manuscript, National Academy of Science, Inputs, effects and fates of petroleum hydrocarbons. in the marine environment, May 21-25, 1973, Washington D.C. 
Matsuda K. and Schnitzer M. (I971) Reactions between fulvic acid, asoil humic material, and dialkyl phthalates, Bul1. Env. Cont. Toxic. 6, 200-203

McAuliffe C. (1966) Solubility in water of paraffin, cycloparaffin, olefin, acetylene, cycloolefin, and aromatic hydrocartons, I. Phys. Chem. 20, 4, 1267-1275

McAuliffe C. (1969) Solubility in water of $C_{9}$ and $C_{10}$
alkane hydrocarbons. Science $163,478-479$.

McDevit W.F., and Long F.A. (1952) The activity coefficient of benzene in aqueous salt solutions, J, Amer. Chem. Soc. 24. 1773

Menzel D.W. and Vacarro R.F. (1964) The measurement of dissolved organic and particulate carbon in sea water, Limnol. Oceanogr. 2, 138-142

Menzel D.W. and Ryther J.H. (1970) Distribution and cycling of organic matter in the oceans, In organic Matter in Natural Waters, (edited by D.W. Hood) Institute of Marine Science, University of Alaska

Meyers P.A. (1972). Association of fatty acids and hydrocarbons with mineral particles in sea water, Ph. D. Thesis, University of Rhode Island

Meyers P.A. and Quinn J.G. (1973) Factors affecting the association of fatty acids with mineral particles in sea water. Geochim. Cosmochim. Acta (in press)

Nissenbaum A. and Kaplan I.R. (1972) Chemical and isotopic evidence for the in situ origin of marine humic substances, Limnol, Oceanogr. 17, 570-582

Ogner G. and Schnitzer M. (1970a) The occurrence of alkanes in fulvic acid, a soil humic fraction, Geochim. Cosmochim. Acta. 34, 921-928

Ogner G. and Schnitzer M. (1970b) Humic substances; Fulvic acid-dialkyl phthalate complexes and their role in pollution, Science 170, 317-318

Ong H.I. and Bisque R.I. (1968) Coagulation of humic colloids by metal ions, Soil Sci. 106, 3, 220-224

Peake E. and Hodgson G.W. (1966) Alkanes in aqueous systems I. Exploratory investigations on the accommodation of $\mathrm{C}_{20}-\mathrm{C}_{33} \mathrm{n}$-alkanes in distilled water and occurrence if natural water systems, J. Amer, Oil Chem. Soc. 43. 4. 215-222

Peake E. and Hodgson G.W.' (1967) Alkanes in aqueous systems II: The accommodation of $\mathrm{C}_{12}-\mathrm{C}_{36}$ n-alkanes in distilled water, J. Amer. Oil Chem. 56c. 394, 12, 696-712 
Pierce R.H. Jr., OIney C.E. and Felbeck Jr. (I971) Pesticide adsorption in soils and sediments, Environ. Letters 1. 157-172

Pierce R.H. Jr. (1973) A study of the mechanism of the adsorption of the chlorinated hydrocarbons in marine sediments, Ph. D. Thesis, University of Rhode Island

Pierce R.H. Jr. and Felbeck G.T. Jr. (1973) A comparison of three methods of extracting organic matter from soils and marine sediments, Proc. Roy. Netherlands Acad. Sci. (in press)

Piret E.I., White R.G., Walther H.C. and Madden A.J. (1960) Some physico-chemical properties of peat humic acids. Proce Roy. Dublin Soc. 1A, 69-79

Prakash A., and Rashid M.A. (1968) Influence of humic substances on the growth of marine phytoplankton: Dinoflagellates, Iimnol. Oceanogr. 13, 598-606

Quinn J.G. and Meyers P. (1971) Retention of dissolved organic acids in sea water by various filters, Limnol. 0ceanogr. 16. 129-131

Rashid M.A. and Prakash A. (1972) Chemical characteristics of humic compounds isolated from some decomposed marine algae, J. Fish. Res. Bd. Canada 29, 55-60

Rashid M.A., Buckley D.E. and Robertson K.R. (1972) Interactions of a marine humic acid with clay minerals and a natural sediment, Geoderma 8, 11-27

Rebhun M. and Manka J. (1971) Classification of organics in secondary effluents, Environ. Sci. Technol. 5,606-609

Riley J.P. and Chester R. (1971) Introduction to Marine Chemistry, Academic Press, Iondon

Schnitzer M. and Ogner G. (1970) The occurrence of fatty acids in fulvic acid, a soil humic fraction, Israel J. Chem. . 505-512

Schnitzer M. and Khan S.U. (1972) Humic Substances in the Environment, Marcel-Dekker Inc., New York

Setschenow J. (1889) Uber die Konsitution der Salzlosungen auf Grund ihres Verhaltens zu Kohlensaure, Z. Physik. Chem. 4,117

Sieburth J. McN. and Jensen A. (1968) Studies on algal substances in the sea I. Gelbstoffe (humic material) in terrestrial and marine waters, J. Exp. Mar. Biol. Ecol. 2. 174-189 
Sheldon R.W. (1972) Size separation of marine seston by membrane and glass fiber filters, Limnol. Oceangr. 17. $494-498$

Skopintsev B.A. (1950) Organic matter in natural waters (water humus), Tr. Inst. Geol. Akad. Nauk. SSSR, 17, $29 p$

Strickland J.D. and Parsons T.R. (1972) A Practical Handbook of sea water analysis, Bulletin 167 (second edition) Fisheries Research Board of Canada, Ottawa

Wagner F.S. (1969) Composition of the dissolved organic compounds in sea water: A review, Cont. Mar. Sci. 14. $115-153$

Wershaw R.I. and Burcar P.J. (1967) Physical-chemical properties of naturally occurring polyelectrolytes-I. Sodium humate, Proc. Third Amer. Water Res. Conf., $351-354$

Wershaw R.I. Burcar P.J., and Goldberg M.C. (1969) Interactions of pesticides with natural organic matter, Environ. Sci. Technol. 3, 271-273

Williams P.J. LeB. (1969) The wet oxidation of organic matter in sea water, Iimnol. Oceanogr. I.4, 292-298

Williams P.M. (1971) The distribution and cycling of organic matter in the ocean, In Organic Compound in Aquatic Environments, (edited by S.J. Faust and J.V. Hunter). Marcel Dekker, New York

Williams P.M. and Gordon I.I. (1970) Carbon 13: carbon 12 ratios in dissolved and particulate organic matter in the sea, Deep Sea Res. 17, 19-2?

Williams P.M. (1967) Sea surface chemistry: Organic carbon and organic and inorganic nitrogen and phosphorus in surface film and subsurface waters, Deep Sea Res. 14. 791.

Winsor P.A. (1956a) Solubilization with amphiphilic compounds I. Manuf. Chemist. , 80-95

Winsor P.A. (1956b) Solubilization with amphiphilic compounds II. Manuf. Chemist, 130-133 